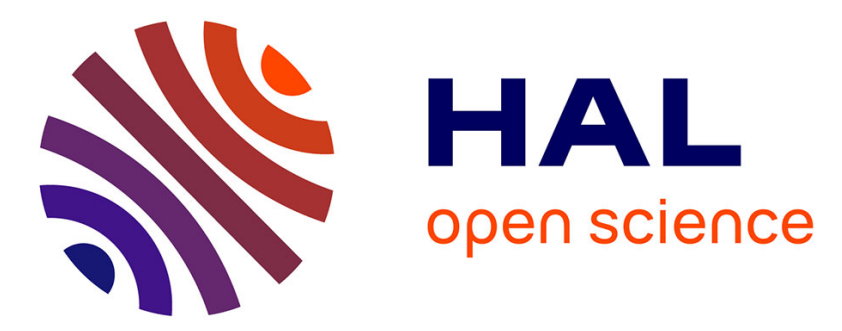

\title{
Quantitative 3D mesoscopic modeling of grain interactions during equiaxed dendritic solidification in a thin sample
}

Antonio Olmedilla, Miha Založnik, Hervé Combeau

\section{- To cite this version:}

Antonio Olmedilla, Miha Založnik, Hervé Combeau. Quantitative 3D mesoscopic modeling of grain interactions during equiaxed dendritic solidification in a thin sample. Acta Materialia, 2019, 173, pp.249-261. 10.1016/j.actamat.2019.05.019 . hal-02381280

\section{HAL Id: hal-02381280 \\ https://hal.univ-lorraine.fr/hal-02381280}

Submitted on 19 Jan 2021

HAL is a multi-disciplinary open access archive for the deposit and dissemination of scientific research documents, whether they are published or not. The documents may come from teaching and research institutions in France or abroad, or from public or private research centers.
L'archive ouverte pluridisciplinaire HAL, est destinée au dépôt et à la diffusion de documents scientifiques de niveau recherche, publiés ou non, émanant des établissements d'enseignement et de recherche français ou étrangers, des laboratoires publics ou privés.

\section{(ㅇ)(1) $\$$}

Distributed under a Creative Commons Attribution - NonCommercial - NoDerivatives| 4.0 


\title{
Quantitative 3D mesoscopic modeling of grain interactions during equiaxed dendritic solidification in a thin sample
}

\author{
Antonio Olmedilla, Miha Založnik, Hervé Combeau \\ Université de Lorraine, CNRS, IJL, F-54000 Nancy, France
}

\begin{abstract}
A 3D mesoscopic envelope model is used to numerically simulate the experimental X-ray observations of isothermal equiaxed dendritic solidification of a thin sample of Al-20 wt\% Cu alloy. We show the evolution of the system composed of multiple grains growing under influence of strong solutal interactions. We emphasize the three-dimensional effects in the thin sample thickness on the growth kinetics, focusing on three aspects: (i) the impact of the third dimension on the solute diffusion, (ii) the influence of the orientation of the preferential grain growth directions $\langle 100\rangle$ on the interactions with the confining sample walls, and (iii) the influence of the grain position along the sample thickness. We demonstrate the importance of considering the three-dimensional structure of the thin samples despite the small thickness. We further show that the mesoscopic envelope model can accurately describe the shape and the time-evolution of the equiaxed grains growing under influence of strong solutal interactions.
\end{abstract}

Keywords: Alloy solidification, dendritic growth, multiscale modeling, model validation

\section{Introduction}

Solidification is an essential passage in materials processing. The final mechanical properties of the solidified and further processed product are greatly dependent on the solidification microstructure of the metallic alloy. Two main solidification structures can be distinguished: columnar and equiaxed [1]. The columnar grain structure is prone to grow in the presence of a thermal gradient whereas an isothermal field encourages the equiaxed dendritic grain growth.

Modeling is fundamental for the understanding and the prediction of the solidification microstructure. Different numerical approaches exist for the simulation of the dendritic grain evolution at the microscopic scale such as the phase-field modeling, used for both equiaxed [2,3] and columnar grain structures [4], the pseudo front tracking [5], the enthalpy method [6], or the microscopic CA [7]. These numerical approaches achieve a highly-detailed description of the dendritic grain morphology with the drawback of high computational cost, which limits the practicable size of simulation domain.

At the mesoscopic scale, several numerical approaches were developed that decrease the computational cost of the simulations by decreasing the level of detail in the description of a dendritic grain. Mesoscopic models allow one to simulate

\footnotetext{
This is a post-peer-review, pre-copyedit version of an article published in Acta Materialia: A. Olmedilla, M. Založnik, H. Combeau, Quantitative 3D mesoscopic modeling of grain interactions during equiaxed dendritic solidification in a thin sample, Acta Mater. 173 (2019), 249-261. The final authenticated version is available online at: https://doi.org/10.1016/j . actamat.2019.05.019.

Email addresses: antonio.olmedilla.aero@gmail.com (Antonio Olmedilla), miha.zaloznik@univ-lorraine.fr (Miha Založnik), herve.combeau@univ-lorraine.fr (Hervé Combeau)
}

much larger domains than microscopic models. Several mesoscopic models exist, such as the dendrite needle network (DNN) model, already applied for equiaxed [8] and columnar dendritic grain growth [9], the cellular-automaton finite-element (CAFE) model $[10,11]$ and the dendrite envelope model. In the envelope model, the complex dendritic structure of a crystal grain is described by means of an envelope, a smooth surface that wraps the tips of the actively growing branches of the dendrite $[12,13,14,15,16]$. The time-evolution of the envelope is computed by means of an analytical dendrite tip growth model coupled to the numerical solution of the solute concentration in the liquid surrounding the grain. This method can accurately predict the morphology of the actual dendritic grains for both columnar $[14,17,16]$ and equiaxed morphologies $[12,13,15]$. The mesoscopic envelope model can be used to simulate solidification phenomena for which interactions at the scale of a group of grains (up to 100 grains) are important, such as grain competition in columnar growth [16], or interactions in equiaxed growth [15]. Apart from direct simulation, such results are very useful for scale bridging to process-scale solidification models [18]. Results of mesoscopic simulations of interacting grains can be used to formulate improved constitutive models of grain growth kinetics for macroscopic models [19, 20].

To determine the fidelity and the limitations of the threedimensional mesoscopic envelope model in representing dendritic solidification kinetics in presence of interactions between grains, reference data is needed. Experimental 2D in situ observations of growth of solidification microstructures [21] in metal alloys, obtained by X-ray imaging, provide interesting reference data. On the other hand, three dimensional modeling of in situ experiments can give further insight into the 3D structure 
of the samples, inaccessible to X-ray transmission projection imaging, and can help in the quantitative analysis of the observations.

With these two objectives in mind we perform mesoscopic envelope simulations of the in situ experiment on equiaxed dendritic solidification of Al-20 wt $\% \mathrm{Cu}$ in a thin sample $(\approx 200 \mu \mathrm{m}$ thickness) of Murphy et al. [22]. We compare the simulations to the experimental real-time in situ X-ray observations. The results show that the three-dimensional mesoscopic envelope model can accurately describe the time-evolution of the grain morphology in case of equiaxed dendritic solidification. We further investigate and quantify the influence of several three-dimensional features of the sample structure on the grain growth: the $3 \mathrm{D}$ nature of the solute diffusion in the confined domain, the orientation of the preferential dendrite growth directions $\langle 100\rangle$ with respect to the sample, and the position of the grain along the sample thickness. We show that despite the small thickness of the sample, all of these aspects have an important impact on the grain growth kinetics and should be accounted for in the quantitative analysis of the experiments.

\section{Mesoscopic Envelope Model}

The main idea of the mesoscopic envelope model is the description of the complex morphology of each equiaxed dendritic grain by means of an envelope, i.e., a virtual smooth surface that connects the tips of the active branches of the dendrite.

For an alloy, the growth of the dendrite tips is governed by the solute flux that the tips eject to the liquid. The Ivantsov analytical solution [23] for the steady-state diffusion around a growing paraboloidal tip is employed in a stagnant film formulation [24] to relate the tip growth Peclet number, $\mathrm{Pe}_{\text {tip }}$, to the supersaturation, $\Omega_{\delta}$, in the liquid at a finite distance, $\delta$, from the tip. This finite distance is the so-called stagnant film thickness. It is an adjustable parameter in the model and its choice is later discussed in more detail. The Peclet number is defined by $\mathrm{Pe}_{\text {tip }}=R_{\text {tip }} V_{\text {tip }} /\left(2 D_{1}\right)$, where $R_{\text {tip }}$ is the tip radius, $V_{\text {tip }}$ is tip growth velocity, and $D_{1}$ is the solute diffusion coefficient in the melt. The dimensionless supersaturation is defined by $\Omega_{\delta}=\left(C_{1}^{*}-C_{\delta}\right) /\left(\left(1-k_{\mathrm{p}}\right) C_{1}^{*}\right)$ where $C_{1}^{*}$ is the liquid equilibrium solute concentration, $C_{\delta}$ is the solute concentration at the distance $\delta$ from the tip, and $k_{\mathrm{p}}$ is the solute partition coefficient. To determine the operating state of the tip $\left(V_{\text {tip }}, R_{\text {tip }}\right)$ a closure condition is added: $R_{\text {tip }}^{2} V_{\text {tip }}=d_{0} D_{1} / \sigma^{*}$, where $\sigma^{*}$ is called the tip selection parameter, $d_{0}=\Gamma /\left(m_{\mathrm{L}} C_{1}^{*}\left(k_{\mathrm{p}}-1\right)\right.$ is the solutal capillary length, $\Gamma$ is the Gibbs-Thomson coefficient, and $m_{\mathrm{L}}$ is the liquidus slope.

The possible growth directions of the dendrite tips, the socalled preferential growth directions, are supposed to be known. A typical cubic crystal dendrite is approximated by six preferential growth directions $(\langle 100\rangle)$ that are perpendicular to each other. The normal envelope growth velocity, $\vec{V}_{\mathrm{n}}$, is then calculated from the local tip speed, $V_{\text {tip }}$, by the relation $V_{\mathrm{n}}=$ $V_{\text {tip }} \vec{n} \cos \theta$, where $\theta$ is the angle between the outward drawn normal to the envelope, $\vec{n}$, and the preferential growth direction that forms the smallest angle with the normal.

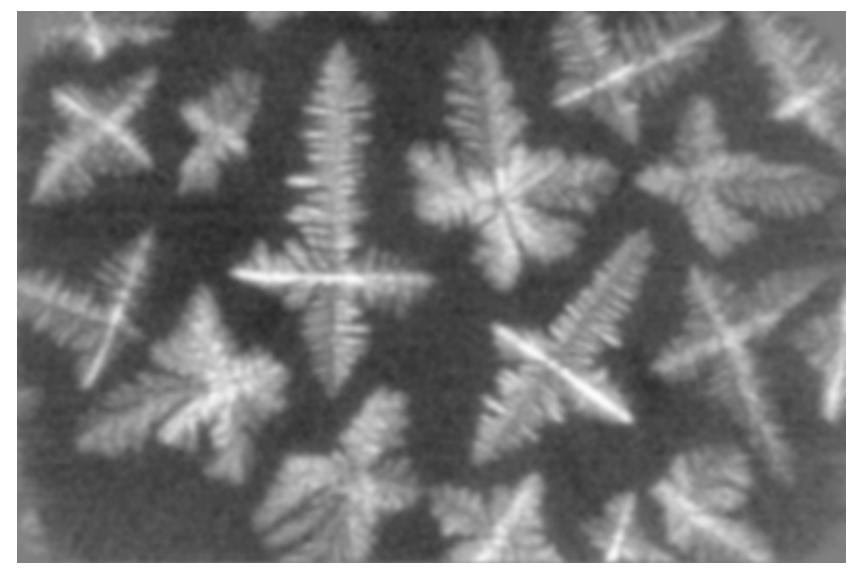

Figure 1: X-ray transmission projection image of growing grains from the XRMON-SOL experiment [22]. Image courtesy of D.J. Browne.

The field of the normal envelope growth velocity, $V_{\mathrm{n}}$, is thus a function of the supersaturation field on a surface that is at a perpendicular outward distance $\delta$ from the grain envelope and of the anisotropy defined by the preferential growth directions. The supersaturation field is obtained by numerically solving the solute diffusion equation in the liquid between the grains.

The phase-field sharp-interface capturing method [25] is used to track the envelope by means of a continuous indicator field, $\phi$, that reproduces a smooth but compact transition from 1 (interior of the envelope) to 0 (exterior of the envelope), following a hyperbolic tangent profile of a characteristic width $W_{\text {tr }}$ [26]. The level set $\phi=\phi_{\text {env }}=0.95$ is used to define the envelope contour, with the internal region of the envelope given by $\phi>\phi_{\text {env }}$. A phase-field propagation equation is used to update the indicator field $\phi$ once the growth velocity field of the grain envelope is computed [25].

The diffusion equation and the phase-field propagation equation were solved by the finite-volume method. For our simulations we use the in-house computer code CrystalFOAM, which employs the finite-volume library OpenFOAM [27]. The complete description of CrystalFOAM is available in $[15,16]$.

\section{Interactions of dendritic grains}

\subsection{In situ experimental observations: the XRMON-SOL ex- periment of Murphy et al.}

In this paper we numerically simulate the experiment of isothermal equiaxed dendritic solidification performed by Murphy et al. [22]. In this experiment the growth of 15 equiaxed dendrites under the influence of solutal interactions was observed in situ by X-ray transmission projection imaging. Growth rates of individual grain envelopes and of dendrite tips were measured from the projected images. Murphy et al. have clearly shown that models of a freely growing dendrite tip cannot explain the observed growth rates and attributed this to the strong solutal interactions and to the confinement due to the thin dimension of the sample.

The experimental setup was composed of a circular disk furnace with heaters arranged circularly around and below the 
sample. The sample had a diameter of $21 \mathrm{~mm}$ and a thickness of $200 \pm 10 \mu \mathrm{m}$ and consisted of an Al-20 wt\% Cu alloy, grain refined with $0.1 \mathrm{wt} \% \mathrm{Al}-5 \mathrm{Ti}-1 \mathrm{~B}$ master alloy. For sufficiently low cooling rates the furnace design ensures a virtually homogeneous temperature in the sample [22]. The furnace was oriented with the thickness direction parallel to the terrestrial gravity, in order to minimize natural convection in the melt. The in situ X-ray monitoring system provides a rectangular observation window of the furnace cavity of $L_{\mathrm{x}}=4124 \mu \mathrm{m}$ and $L_{\mathrm{y}}=2746 \mu \mathrm{m}$ in the $x$ and $y$ directions, respectively. The sample was first completely melted and then cooled at a constant cooling rate of $0.05 \mathrm{~K} / \mathrm{s}$ in isothermal conditions. During the cooling stage 15 equiaxed dendritic grains progressively nucleated in the observation window, shown in Fig. 1. Their growth was strongly affected by the interactions among them and was reported for a duration of $125 \mathrm{~s}$ from the nucleation of the first grain. Outside the observation window, other grains may have nucleated and grown but no information is available about them.

In next subsection we describe in detail the simulation domain, the boundary conditions, and the numerical parameters adopted.

\subsection{Mesoscopic modeling: reference simulation case $(R C)$}

We establish a rectangular prismatic simulation domain of length and width equal to those of the experimental observation window, $L_{\mathrm{x}}=4124 \mu \mathrm{m}$ and $L_{\mathrm{y}}=2746 \mu \mathrm{m}$, respectively, and a sample thickness of $L_{\mathrm{z}}=200 \mu \mathrm{m}$. The simulation domain and the global reference frame $x-y-z$ are shown in Fig. 2a.

In the model, the 15 grains are initialized as spherical seeds of diameter $D_{\text {ini }}=90 \mu \mathrm{m}$, as shown in Fig. 2a. The $x$ and $y$ coordinates of the seed centers are known from the experiments and are given in [22], whereas the position in the sample thickness, the coordinate $z$, is unknown. In the reference case (RC), all seeds are positioned at half thickness of the sample, i.e., at $z=0$.

Each grain has its own body orthonormal reference frame $x_{\mathrm{b}}-$ $y_{\mathrm{b}}-z_{\mathrm{b}}$ that is attached to the initial seed. The preferential growth directions of the crystal are defined in the body reference. For the material under consideration these are the set of directions $\langle 100\rangle$, i.e., six directions perpendicular to each other. The body frames of the 15 grains may be rotated around the three global axes $x, y$ and $z$. In an experiment similar to XRMON-SOL, Becker [28] has shown that for some grains the rotations can be identified by careful analysis of the X-ray images. Generally, however, it may be difficult to determine the three rotations experimentally from the transmission "footprint" of the grain. For the simulated experiment, the rotations around the $z$ axis have been identified in [22], but the rotations around the $x$ and $y$ directions were not determined. For RC we assume only rotations around the $z$ axis, as given in [22].

The nucleation of the grains was not directly observed in the experiment due to limitations of image resolution and contrast. For each grain the time when it becomes observable (when it reaches a size of approximately $50 \mu \mathrm{m}$ ) is reported in [22] and the evolution of its size is also given. Using this data, the nucleation of each grain was triggered in the simulations at the

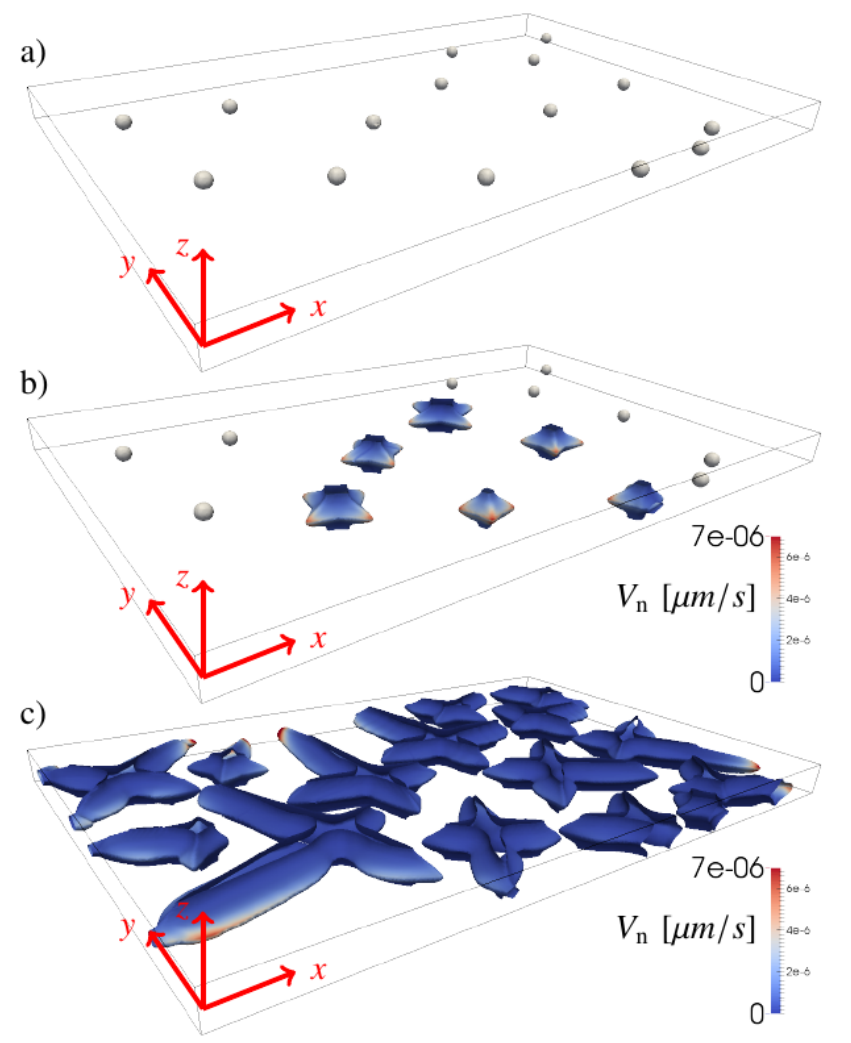

Figure 2: 3D snapshots of the simulation domain and growing envelopes of 15 equiaxed grains (RC). a) initial configuration with the seeds, $t_{\mathrm{sim}}=0, \mathrm{~b}$ ) $t_{\mathrm{sim}}=50 \mathrm{~s}$, and c) $t_{\mathrm{sim}}=130 \mathrm{~s}$. The color map indicates the normal growth velocity of the envelopes, $V_{\mathrm{n}}$. 
Table 1: Thermophysical properties and model parameters used in the simulations.

\begin{tabular}{llr}
\hline Thermophysical properties & & \\
Nominal concentration & $C_{0}$ & $20 \mathrm{wt} \%$ \\
Liquidus slope & $m_{l}$ & $-3.5 \mathrm{~K} / \mathrm{wt} \%$ \\
Partition coefficient & $k_{C u}$ & 0.12 \\
Liquid diffusion coefficient & $D_{1}$ & $2.8 \times 10^{-9} \mathrm{~m}^{2} / \mathrm{s}$ \\
Gibbs-Thomson coefficient & $\Gamma_{\mathrm{sl}}$ & $2.4 \times 10^{-7} \mathrm{Km}$ \\
& & \\
Model parameters & & \\
Tip selection parameter & $\sigma^{*}$ & 0.0253 \\
Stagnant film thickness & $\delta$ & $20 \mu \mathrm{m}$ \\
\hline
\end{tabular}

time that corresponds to an equivalent grain envelope diameter of $D_{\text {ini }}=90 \mu \mathrm{m}$. Prior to such a nucleation event the volume of a seed is fully liquid. The origin of the simulation time, $t_{\text {sim }}=0$, is the nucleation instant of the first grain. The simulated time is 130 seconds (see Fig. 2c).

The temperature field is assumed uniform and the cooling rate constant. In this way, the temperature is given by: $T=T_{\text {ini }}+\dot{T} t_{\text {sim }}$ with $\dot{T}=-0.05 \mathrm{~K} / \mathrm{s}$. The initial temperature, $T_{\text {ini }}=601.7^{\circ} \mathrm{C}$, was determined from the data available in [22]. The initial concentration field is uniform and corresponds to the nominal concentration of the alloy, $C_{0}=20 \mathrm{wt} \%$. All thermophysical properties of the alloy were taken from Ref. [22] and references therein and are summarized in Table 1. Additionally, for RC we estimate the selection parameter by the marginal stability criterion [29]: $\sigma^{*}=(2 \pi)^{-2} \approx 0.0253$.

In this paper, the melt convection flow is not accounted for. Comparisons with an experiment performed in microgravity with the same setup and under identical conditions [30] suggest that melt convection has only a minor impact on the grain growth in this specific experimental configuration. Additionally, the initial positions of the grain centroids (seed centers) and the grain orientations remain fixed during the simulation. We neglected the small displacements of the grains that were observed in the experiment and presumably occurred due to liquid feeding and mechanical impingement of the neighboring grains $[22,30]$. These displacements are minimal and are of no significance for the grain orientation that is investigated in Sec. 4.3 .

The effect of wetting at the solid-liquid-crucible triple line on the tip growth kinetics was not considered. In case of small wetting angles this effect can have a significant influence on the tip speed [31].

A condition of zero diffusion flux (zero derivative of liquid concentration, $C_{1}$ ) is used on all domain boundaries. For the four boundaries that represent the limits of the field of view in the experiment this is of course merely an approximation, used due to lack of more realistic data. Additionally, for the indicator field $\phi$ and for the calculation of its propagation velocity all the boundaries are defined as symmetry planes. This imposes $\nabla \phi \cdot \vec{n}=0$, where $\vec{n}$ is the unit normal vector of the boundary and implies that the dendrite envelopes "wet" the domain a)

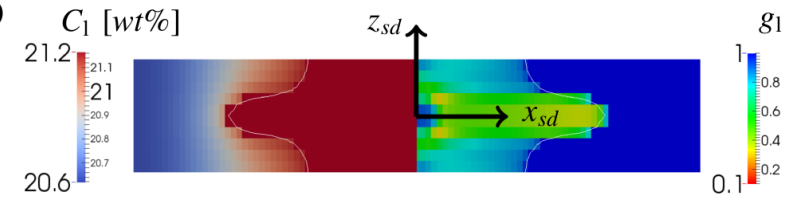

b)

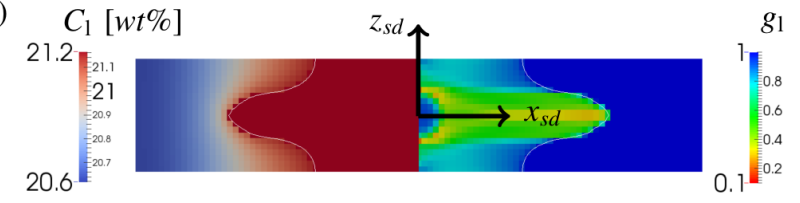

c)

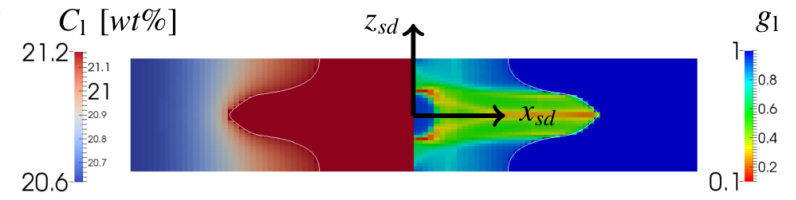

Figure 3: Mesh sensitivity of the representation of the 3D grain in the sample thickness. A slice across the 3D domain by a (100) plane containing the grain center is shown for three simulations with different mesh spacings. The liquid concentration, $C_{1}$, is shown in the left and the liquid fraction, $g_{1}$, in the right half; the thin white line is the grain envelope. 3D growth of a single dendritic grain was simulated in a small domain of dimensions $L_{\mathrm{sd}, \mathrm{x}}=L_{\mathrm{sd}, \mathrm{y}}=1000 \mu \mathrm{m}$, and $L_{\mathrm{sd}, \mathrm{z}}=200 \mu \mathrm{m}$ and identical thermodynamic properties and model parameters as in RC were used. Mesh spacing: a) $\Delta z_{s d}=20 \mu \mathrm{m}$, b) $\Delta z_{s d}=10 \mu \mathrm{m}$ (same as in RC), and c) $\Delta z_{s d}=5 \mu \mathrm{m}$. The mesh spacing in the other directions is $\Delta x_{s d}=\Delta y_{s d}=10 \mu \mathrm{m}$, identical for all three simulations.

walls with an angle of $90^{\circ}$. This is a numerical effect that can be reduced by a finer grid. We have shown however, that the "wetting" effect is not critical and does not need to be completely eliminated to obtain accurate results. It is sufficient that the grid be fine enough to capture the three-dimensional shape of the dendrite around the actively growing portions of the envelope - typically the primary and secondary tips. An accurate description of these zones is crucial in order to resolve the three-dimensional rejection of solute around the growing portions of the envelope and its impact on the envelope growth. In parts of the envelope where the growth stops because of interaction with the sample walls, accurate resolution of the envelope shape is not important. Any remaining liquid between the grain and the wall will effectively be enriched up to the equilibrium concentration. Whether this liquid is represented by a thin film between the envelope and the wall, or is engulfed by the envelope does not alter the prediction of the grain growth.

A grid convergence study is carried out to investigate the influence of the mesh spacing on the representation of the grain in the sample thickness (see Fig. 3). In this study the growth of a single grain is simulated in a small domain (sd) of dimensions $L_{\mathrm{sd}, \mathrm{x}}=L_{\mathrm{sd}, \mathrm{y}}=1000 \mu \mathrm{m}$ and $L_{\mathrm{sd}, \mathrm{z}}=200 \mu \mathrm{m}$ with identical thermophysical properties, model parameters and cooling rate as in RC. In these simulations the center of the fixed grain is located at the center of the small domain and grain principal growth directions are parallel to the small domain edges. This grid convergence study shows that even meshes much coarser than those used in subsequent simulations accurately reproduce the grain growth.

Eventually, for our 15-grain simulation domain, a uniform fi- 
nite volume mesh was used, with the number of elements in the three directions being: $L_{\mathrm{x}} / \Delta x=378, L_{\mathrm{y}} / \Delta y=252$ and $L_{\mathrm{z}} / \Delta z$ $=20$. This gives a mesh size of around $10 \mu \mathrm{m}$ in all directions. The mesh size used in the mesoscopic envelope model should be of the order of $1 / 10$ of the smallest diffusion length to be represented during the simulation. This usually leads to a mesh size of the order of $\sim D_{1} /\left(10 V_{\max }\right)$, where $V_{\max }$ is the highest envelope propagation velocity (typically a primary tip velocity). The highest observed tip velocities in the experiment are of the order of $\sim 20 \mu \mathrm{m} / \mathrm{s}$, which would impose a mesh size of $\leq 14 \mu \mathrm{m}$.

The initial seed diameter, $D_{\text {ini }}$, is related to the mesh size. In order to have an accurate description of the envelope curvature during the initial stages of growth, the seed diameter must be set to $D_{\text {ini }} \approx 6 W=6 \sqrt{2} \Delta x$ [15], where $W$ is the characteristic width of the transition of the indicator field $\phi$ at the envelope ("interface thickness").

The stagnant film thickness, $\delta$, which controls the matching of the dendrite tip model to the numerical solution of the solute concentration field, is a key parameter of the model [32, 15]. The detailed explanation of the calibration of this parameter, $\delta$, is given in Appendix A.

\section{Simulation results and discussion}

In this section we present and discuss the mesoscopic simulation results. We focus on assessing the influence of the orientation of the grains and their position in the thickness of the sample. These parameters cannot be controlled in the experiments and are difficult to determine by projection imaging. Yet, as we will show, they have a major influence on the observed grain growth rates and shapes. The information on the threedimensional structure of the sample is thus crucial to extract quantitative information from the experiments.

We present the results of the 3D simulations in form of numerical transmission footprints that can be compared to the experimental images. The numerical transmission is carried out using the Beer-Lambert law. Assuming the incident beam to be parallel to the direction $z$, the transmittance, $T_{\mathrm{I}}$, at position $(x, y)$ and time $t$ for a given beam energy is given by $T_{\mathrm{I}}(x, y, t)=\exp \left(-\int_{-L_{z} / 2}^{+L_{z} / 2} \mu\left(C_{\mathrm{Cu}}(x, y, z, t)\right) d z\right)$, where the absorption coefficient, $\mu$, is assumed to depend only on the local average solute concentration. Further details are given in Appendix B.

\subsection{Impact of the three-dimensional solute diffusion}

The reference simulation case (RC) is that described in Section 3.2: the grains are seeded at mid-thickness of the 3D domain, one of the $\langle 100\rangle$ preferential growth directions is aligned with the $z$ direction and the rotations around the $z$ direction are taken from [22]. The numerical Beer-Lambert transmission of the RC at the final time, $t_{\text {sim }}=130 \mathrm{~s}$, is shown in Fig. 4a. Grains can be clearly identified due to the lower transmission of the solute-lean solid phase. In each grain, three regions can be distinguished: (i) the initial seed, (ii) the primary dendrite arms with lighter colors in the gray scale $\left(T_{\mathrm{I}} \approx 0.65\right)$ corresponding a)

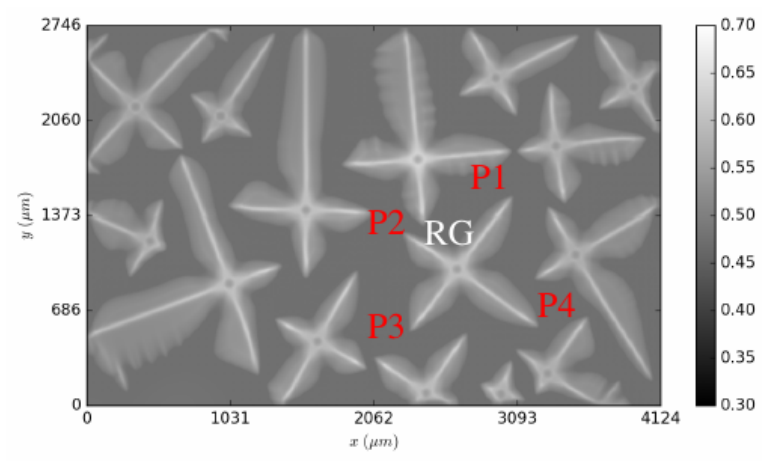

b)

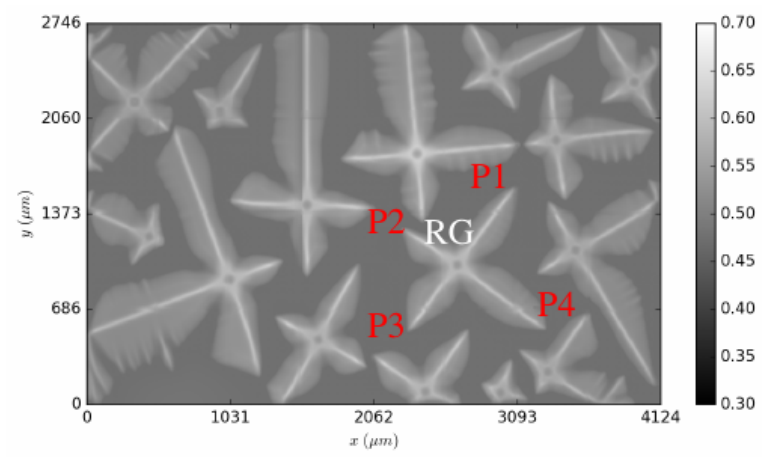

c)

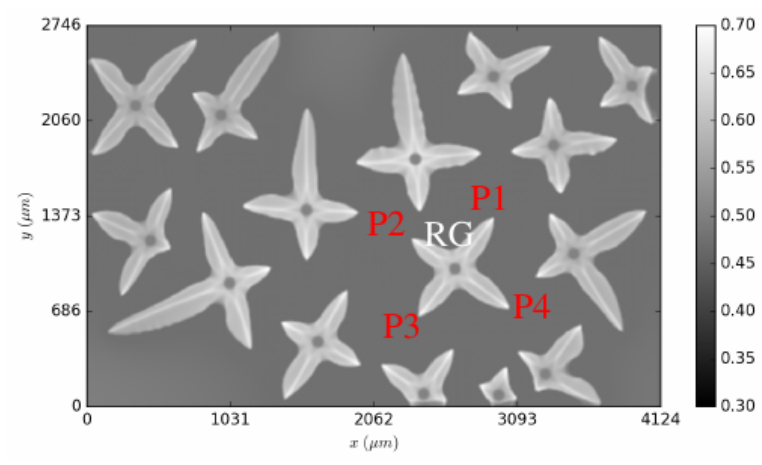

Figure 4: Numerical Beer-Lambert transmission at the final instant $t_{\text {sim }}=130 \mathrm{~s}$ for a) reference case ( $\mathrm{RC}$ ), 3D simulation with $\sigma^{*}=0.0253$, b) $\mathrm{C} \sigma^{*}$ case, 3D simulation with a higher value of the selection parameter $\left(\sigma^{*}=0.035\right)$, and c) C2d case, $2 \mathrm{D}$ simulation with $\sigma^{*}=0.0253$. The reference grain, RG, is indicated. The gray scale bar refers to the transmission coefficient, $T_{\mathrm{I}}$. 
to a low copper concentration $(\lesssim 10 \mathrm{wt}$.\%), and (iii) the secondary dendrite arm region with darker colors $\left(T_{\mathrm{I}} \approx 0.57\right)$ corresponding to a "mixture" of solid and solute-enriched intradendritic liquid. The melt presents the darkest color $\left(T_{\mathrm{I}} \approx 0.5\right)$ with solute concentration of approximately $21 \mathrm{wt} . \%$. The shape and size of the grains, and the transmission levels are very similar to the experimental image (Fig. 1).

Because of the small thickness of the confinement we could argue that the solute concentration gradients in the $z$ directions quickly vanish. The diffusion time across the sample midthickness, $L_{\mathrm{z}}^{2} /\left(4 D_{1}\right) \approx 3 \mathrm{~s}$, is indeed much smaller than the diffusion time across the smallest observed tip diffusion length $\left(D_{1} / V_{\text {tip,max }}\right.$ at the highest observed tip speed in the experiment, $\left.V_{\text {tip, } \max } \approx 16 \mu \mathrm{m} / \mathrm{s}\right)$, which is $D_{1} / V_{\text {tip,max }}^{2} \approx 12 \mathrm{~s}$. The question is, therefore, whether the solute diffusion at the sample scale is not effectively two-dimensional, while the dendrite tip, much smaller than the sample thickness remains clearly threedimensional. We investigated the effect of the thin direction $z$ on the solute diffusion and consequently on the grain growth kinetics by comparing the $3 \mathrm{D}$ simulation (RC) to a $2 \mathrm{D}$ simulation case (C2d). In C2d the solute diffusion is solved in two dimensions (in the $x-y$ plane) assuming zero gradients of solute concentration in the liquid along the direction $z$. For the envelope growth the same three-dimensional tip growth kinetics model is used as in RC. Such simulations could be interesting because of the substantially smaller computation time. The mesh was composed by approximately $10^{5}$ volume elements $\left(L_{\mathrm{x}} / \Delta x=378\right.$, $L_{\mathrm{y}} / \Delta y=252$, and $\left.L_{\mathrm{z}} / \Delta z=1\right)$, which is 20 times less compared to the three-dimensional simulations. The computational cost, however, decreased by 768 times. C2d was run in a single processor in around 12 hours whereas the 3D simulation needed around 288 hours on 32 processors.

In Fig. 4c, the numerical Beer-Lambert transmission of C2d at $130 \mathrm{~s}$ is shown. Large differences compared to both the threedimensional case and to the experiment are found. The most striking difference is the much smaller size of the equiaxed grains at the same instant. The reason is that the dendrite tips in a 2D diffusion field grow slower than if the solute diffuses around $3 \mathrm{D}$ envelopes. This is because the solute concentration gradients resulting from diffusion around a 3D envelope are higher than in two dimensions, where the envelope is plane in the $z$ direction. The effect can be understood through Fig. 3, where the solute concentration field in the thickness of the 3D sample is shown. In C2d, the transmission image shows a higher level of contrast between the envelopes and the surrounding liquid. Since there is no thickness integration to compute the transmission $\left(T_{\mathrm{I}}=\exp \left(-\mu L_{\mathrm{z}}\right)\right)$ in this case, more vivid transmission images are obtained.

In this way we show that the sample thickness $L_{\mathrm{z}}-$ despite being smaller than the tip diffusion lengths, ranging from $190 \mu \mathrm{m}$ to $1000 \mu \mathrm{m}$ - plays a fundamental role on the solute diffusion and consequently on the grain growth kinetics.

In RC we have used a common estimate for the selection parameter: $\sigma^{*}=(2 \pi)^{-2}$. Yet the selection parameter is not universal and depends on the anisotropy of the surface energy [33]. It can also be modified by the effect of the confinement of the walls [34] but only in very thin geometries, which is not the

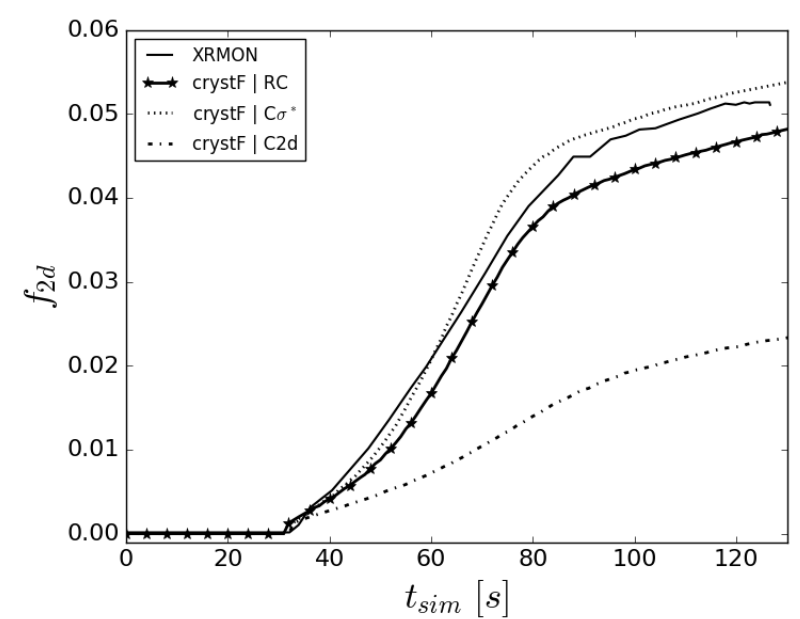

Figure 5: Evolution of the dimensionless envelope projected area, $f_{2 \mathrm{~d}}$, over time for the reference grain, $\mathrm{RG}$, where $f_{2 \mathrm{~d}}$ is the ratio of the projected grain area to the projected domain area $\left(f_{2 \mathrm{~d}}=A_{2 \mathrm{~d}} /\left(L_{\mathrm{x}} L_{\mathrm{y}}\right)\right)$. Two different threedimensional simulation cases are shown: the reference case (crystF $\mid \mathrm{RC}$ ) and the case of higher $\sigma^{*}=0.035\left(\mathrm{crystF} \mid \mathrm{C} \sigma^{*}\right)$. The two-dimensional simulation case is also shown (crystF $\mid \mathrm{C} 2 \mathrm{~d}$ ). Additionally, the experimental results of Murphy et al. [22] are also shown (XRMON).

case here. As shown by Clarke et al. [35] by phase-field simulations of columnar growth in $200 \mu \mathrm{m}$ thin samples, the product $R_{\text {tip }}^{2} V_{\text {tip }} \sim 1 / \sigma^{*}$ remains constant at least down to confinement thicknesses that are five times the primary tip radius. For the present case an estimate of the dendrite tip radius is obtained by $R_{\text {tip }}=\sqrt{d_{0} D_{1} /\left(\sigma^{*} V_{\text {tip }}\right)}$, with $d_{0} \approx \Gamma /\left(m_{\mathrm{L}} C_{0}\left(k_{\mathrm{p}}-1\right)\right.$. This gives radii between $5 \mu \mathrm{m}$ and $10 \mu \mathrm{m}$ for the four tips of the RG during the initial growth stage, before the solutal interactions strongly slow down the tips, i.e., up to $t \approx 80 \mathrm{~s}$. The primary tip radii are thus 10 to 20 times smaller than the confinement thickness. Another reason for the variation of $\sigma^{*}$ is the transient nature of the growth. Due to the cooling, the supersaturation of the tip is evolving throughout the whole growth process and in principle the tip never grows in a steady-state growth mode. Recently, Boukellal et al. [3] studied transient equiaxed growth in confined geometries under similar cooling conditions by phasefield simulations and have shown that $\sigma^{*}$ can vary by more than $30 \%$ of the average value during growth.

Accurate data on $\sigma^{*}$ for Al-Cu alloys are not available in literature. Tourret et al. [36] estimated a value of $\sigma^{*}=0.03$ for an $\mathrm{Al}-24.3 \mathrm{wt} \% \mathrm{Cu}$ alloy, based on a surface energy anisotropy of $\epsilon_{4}=0.012$. In order to check the sensitivity of the predicted time evolution of the solidification microstructure to the selection parameter, a complementary simulation case (Case $\mathrm{C} \sigma^{*}$ ) is considered. In $\mathrm{C}^{*}$ a $40 \%$ larger value of the selection parameter is used, $\sigma^{*}=0.035$, all other parameters are identical to those of RC. The numerical Beer-Lambert transmission for $\mathrm{C}^{*}$ is shown in Fig. $4 \mathrm{~b}$ and we can observe similar grain shapes and transmission levels as in RC. We can infer that the selection constant has a negligible influence on the morphology of the grains. As we show later, it slightly affects the growth speed. 


\subsection{Envelope growth rate and tip speed}

With the exception of one grain (marked "RG" - reference grain - in Fig. 4) all grains are adjacent to the boundaries of the field of view and thus under influence of interactions with grains that are not visible and cannot be accounted for. Detailed quantitative comparisons with the experimental results will therefore focus on the RG. This grain is surrounded by other equiaxed grains and interacts with the top and bottom sample walls. These interactions are fully described in the simulations.

In Fig. 5 we show the time-evolution of the projected envelope area fraction, $f_{2 \mathrm{~d}}$, which is the envelope area visible by the numerical Beer-Lambert transmission, $A_{2 \mathrm{~d}}$, divided by the surface area of the field of view $\left(L_{\mathrm{x}} \times L_{\mathrm{y}}\right)$. A very similar evolution of $f_{2 \mathrm{~d}}$ over time is found for $\mathrm{RC}, \mathrm{C} \sigma^{*}$ and the experimental observations of [22]. RC shows slightly lower values of $f_{2 \mathrm{~d}}$ over time than the experiment, whereas $\mathrm{C}^{*}$ shows slightly higher values. For $\mathrm{C} 2 \mathrm{~d}$ a much lower projected envelope area is found, clearly underestimating the growth rate.

A second quantitative analysis is carried out to compare the predicted growth of the envelope to the experimental observations in [22] in more detail. In Figs. 6a-b we depict the time evolution of the primary arm length, $L_{\mathrm{p}}$, of the four visible branches, P1-P4, of the reference grain, RG. For a better comprehension, the results are separated in two sets: (i) the primary arms $\mathrm{P} 1$ and $\mathrm{P} 3$ in Fig. 6a, and (ii) the primary arms P2 and P4 in Fig. $6 b$.

The RC results (three-dimensional with $\sigma^{*}=0.0253$ ) show a final primary arm length of approximately $600 \mu \mathrm{m}$ for P1 and $\mathrm{P} 3$ with a slightly shorter $\mathrm{P} 2$ and a slightly longer $\mathrm{P} 4 . \mathrm{C} \sigma^{*}$ (with a $40 \%$ larger value of the selection constant) leads to slightly longer arms $\mathrm{P} 1$ and $\mathrm{P} 4$, longer by $4 \%$ and $9 \%$, respectively, and similar length for $\mathrm{P} 2$ and $\mathrm{P} 3$. In case of $\mathrm{C} 2 \mathrm{~d}, \mathrm{P} 2$ is by approximately $25 \%$ shorter than in $\mathrm{RC}$, whereas P1, P3, and P4 are up to $50 \%$ shorter.

In both experimental and simulation results, three different growth regimes are identified: (i) initial transient where the growth rates increases, (ii) steady-state growth, and (iii) final transient where the growth decelerates. The three-dimensional simulations accurately predict the end instant of the steady-state regime at approximately $70 \mathrm{~s}$, which corresponds to the onset of an important solutal interaction between the grains. During the steady-state regime, the primary arm length evolves almost linearly with time (see Figs. 6a-b). The steady-state growth regime finishes once the solutal interaction with neighboring grains become important as a consequence of the increment of the soluteenriched liquid between the grains.

However, the projected shape of the reference grain (RG) obtained by the three-dimensional cases ( $\mathrm{RC}$ and $\left.\mathrm{C} \sigma^{*}\right)$ is considerably different than in the experiments. In the experimental observations of [22], P1 and P3 are somewhat longer than in our simulations whereas P2 and P4 are much shorter. We have already shown that the selection constant plays a negligible role on the final grain shape. The failure to predict the correct grain shape thus cannot be attributed to uncertainty of the value of $\sigma^{*}$. The best fit for the length of arms P2 and P4 is actually
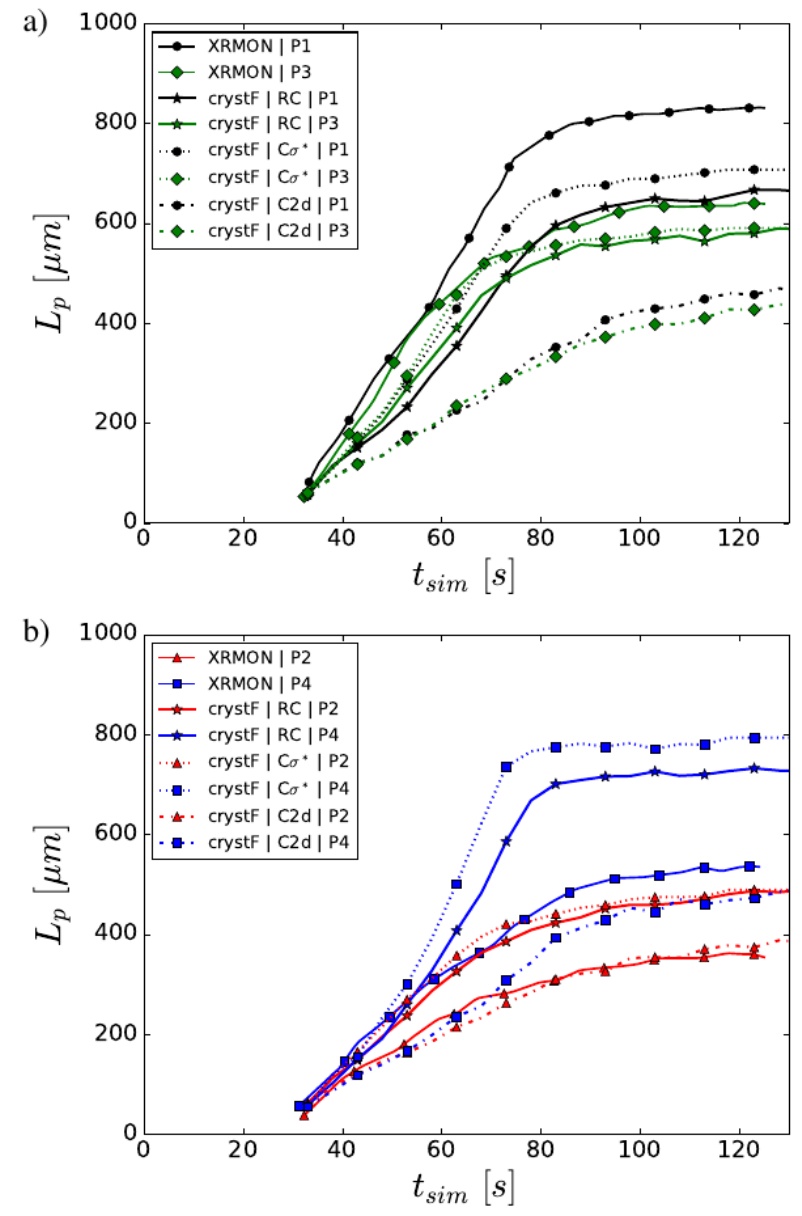

Figure 6: Evolution of equiaxed primary arm, $L_{\mathrm{p}}$, over time for the reference grain, RG. Two different three-dimensional simulation cases are shown: the reference case (crystF $\mid \mathrm{RC}$ ) and the case of higher $\sigma^{*}=0.035\left(\right.$ crystF $\left.\mid \mathrm{C} \sigma^{*}\right)$. The two-dimensional simulation case is also shown (crystF $\mid \mathrm{C} 2 \mathrm{~d}$ ). Additionally, the experimental results of Murphy et al. [22] are also shown (XRMON). 
obtained by the 2D simulation, which however completely fails in predicting the initial growth transient (see Fig. 6b).

It seems that the much slower growth speed of arms P2 and $\mathrm{P} 4$ cannot be explained by a physical or model parameter that exhibits a similar influence on all dendrite tips. These two arms appear to be slowed down by an effect that is particular to them. The large extent of the liquid zones remaining in front of the tips $\mathrm{P} 2$ and $\mathrm{P} 4$ that can be observed in the experimental images (Fig. 1) indicates that the slowdown is not due to solutal interactions with the neighboring grains. Furthermore, we observe a tip speed significantly slower than that of tips $\mathrm{P} 1$ and $\mathrm{P} 3$ right from the beginning, before any interaction occurs.

A reason for the differences in the growth of the arms can be due to three-dimensional effects that are not directly visible on the numerical Beer-Lambert transmissions, such as a misalignment of the grain preferential growth directions $\langle 100\rangle$ with respect to the $z$ direction, and the position of the grain in the sample thickness. We explore these effects in the next section.

\subsection{Impact of the three-dimensional effects of grain rotation and position along the sample thickness}

The preferential growth directions $\langle 100\rangle$ of the grains observed in the experiment can have any arbitrary spatial orientation with respect to the vertical direction $z$ of the sample. Because of the small thickness of the sample, the interaction of a dendrite arm with the confining walls is very sensitive to the orientation of its growth direction. Furthermore, the position of the grain in the sample thickness can influence the confinement that the solute diffusion around the grain "feels" and may affect its growth speed. The primary solid phase growing from an Al-20 wt $\% \mathrm{Cu}$ melt has a lower density than the liquid and the grains can be expected to float towards the top wall [30, 37, 38]. In this section we analyze the effects of rotation and of position in the sample thickness on the growth and we show that they may play a fundamental role on the time-evolution of the grain shape.

To investigate the influence of the rotation the $\mathrm{RC}$ simulation was used as starting point and the RG was rotated around the axis $\hat{e}_{\text {rot }}$, a line that runs through tips P1 and P3. $\hat{e}_{\text {rot }}$ is contained in the $x-y$ plane and is coincident with the grain body coordinate axis $x_{\mathrm{b}}$ (see Figs. 7 and 8a). We run three cases with three different rotation angles around $\hat{e}_{\text {rot }}: 15^{\circ}(\mathrm{C} 15), 30^{\circ}(\mathrm{C} 30)$, and $45^{\circ}(\mathrm{C} 45)$.

In Figs. 7a-c, we show the numerical Beer-Lambert transmission at the final instant for $\mathrm{C} 15, \mathrm{C} 30$, and $\mathrm{C} 45$. The rotation around $\hat{e}_{\text {rot }}$ has a clear effect on the shape of the grain under study. The primary arms $\mathrm{P} 1$ and $\mathrm{P} 3$ remain in the plane $x-y$, whereas a new notation is used for the other two visible primary arm tips: P26 and P45. P26 is the result of the projection of P2 and P6 on the plane $x-y$, where P6 grows in direction $(0,0,-1)$ in body coordinates, and $\mathrm{P} 45$ is the result of the projection of $\mathrm{P} 4$ and P5 on the plane $x-y$, where P5 grows in direction $(0,0,1)$ in body coordinates. The higher the rotation angle, the shorter are P26 and P45, however with only negligible effect on P1 and $\mathrm{P} 3$. Additionally, the bright line joining P1 and P3 becomes darker with the rotation angle, whereas the line joining P26 and P45 becomes brighter. A similar strong brightness difference a)

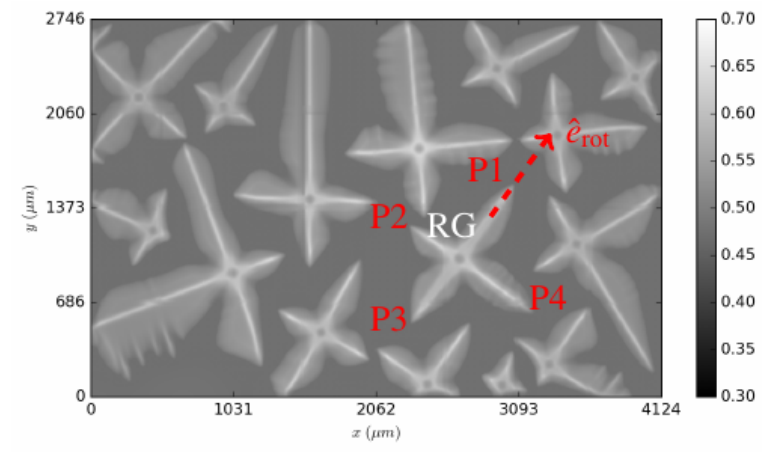

b)

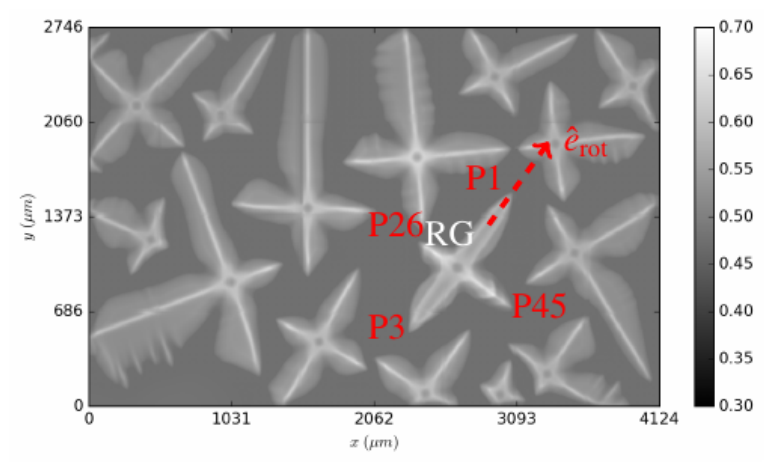

c)

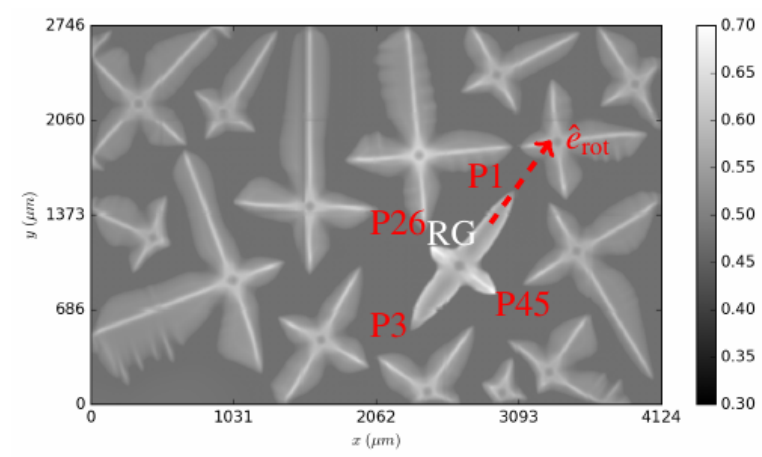

Figure 7: Numerical Beer-Lambert transmission at the final instant $t_{\mathrm{sim}}=130 \mathrm{~s}$ for a rotation angle of RG around the axis $\hat{e}_{\text {rot }}$ by: a) $15^{\circ}(\mathrm{C} 15)$, b) $30^{\circ}$ (C30), and c) $45^{\circ}(\mathrm{C} 45)$. The gray scale bar refers to the transmission coefficient, $T_{\mathrm{I}}$. 
a)

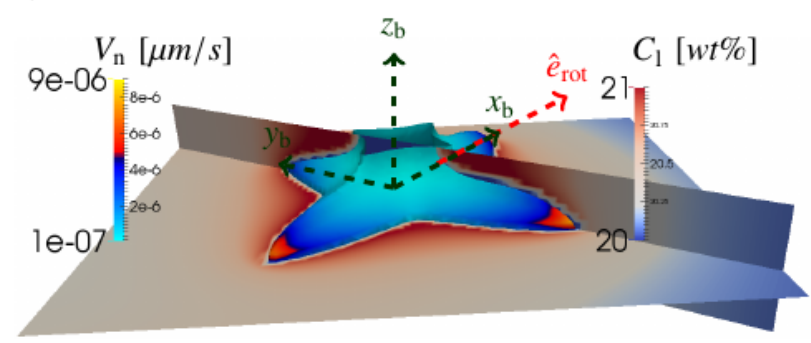

b)

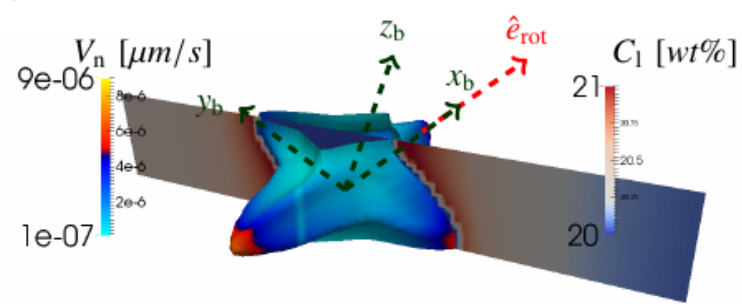

c)

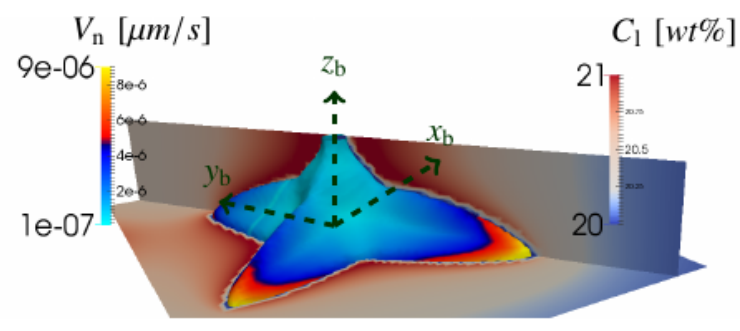

d)

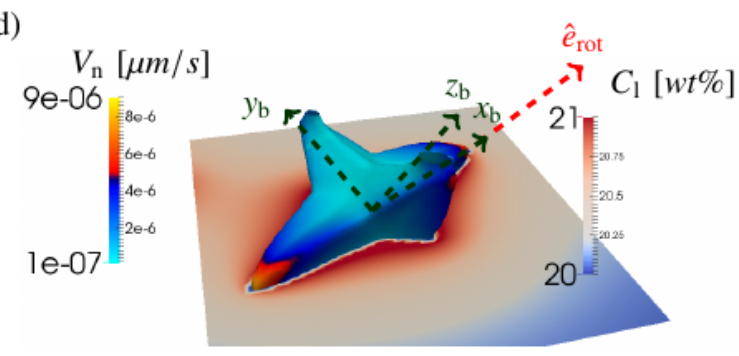

Figure 8: RG at the time of 60 s for: a) the reference simulation case (RC) that is symmetric with respect to the $x-y$ plane, $\mathrm{b}$ ) the case with RG rotated $30^{\circ}(\mathrm{C} 30)$, non symmetric with respect the $x-y$ plane. The rotation direction $\hat{e}_{\text {rot }}$ is contained in the $x-y$ plane and normal to the vertical plane illustrated. The image (c) shows the simulation case C100 where the center of RG is set at the $z=-100 \mu \mathrm{m}$ wall of the sample. The image (d) shows simulation case $\mathrm{C} 45+100$ where the center of RG is set at the $z=-100 \mu \mathrm{m}$ wall of the sample, and the rotation axis $\hat{e}_{\text {rot }}$ contained in the plane $z=-100 \mu \mathrm{m}$. between the two lines can be seen in the experimental images (see Fig. 1). In the experiment, an alignment of secondary dendrite arms in a plane perpendicular to the $x-y$ plane amounts to a large proportion of solute-lean solid in the sample thickness. Such an alignment therefore results in a brighter transmission line along the primary dendrite trunk. Conversely, if the secondary arms lie in a plane oblique to the $x-y$ plane, the amount of solid in the sample thickness is reduced and the primary trunk appears darker. In the simulations these effect is reproduced via the distribution of solid fraction in the dendrite envelope and the 3D envelope shape.

The rotation of RG is shown in more detail in Figs. $8 \mathrm{a}$ and $\mathrm{b}$ for $\mathrm{RC}$ and $\mathrm{C} 30$, respectively, during the steady-state regime of the grain growth, at $t_{\mathrm{sim}}=60 \mathrm{~s}$.

For a zero rotation angle (RC) the dendrite is symmetric with respect to the plane $x-y$. The solute concentration field in the liquid is also shown in two planes: in the plane $x-y$ and in the vertical plane that is perpendicular to $\hat{e}_{\text {rot }}$ and passes along the seed center. A difference of concentration between the tips and the far field, $\overline{\Delta C_{1}}$, of approximately $1 \%$ is observed. For rotation angles greater than zero, a strong deformation of the dendrite envelope can be observed, with four of the preferential directions touching the top or bottom walls.

We also investigate the impact of rotation on the RG quantitatively. We show the evolution of the projected grain area, $f_{2 \mathrm{~d}}$, over time in Fig. 9. The larger the rotation angle, the smaller is $f_{2 \mathrm{~d}}$; for all rotations smaller projected areas than the experimental observations are obtained.

In Fig. 10 we show the time-evolution of the projected primary arm length for all the grain arms. The rotation has virtually no influence on P1 and P3 (Fig. 10a). As in the RC, we obtain slightly shorter arms than in the experiments, by $24 \%$ for P1 and by $10 \%$ for P3, independently of the rotation angle. For the projected arms P26 and P45 resulting from the four branches that grow perpendicular to the rotation axis, significantly shorter lengths are obtained. The length of both P26 and P45 decreases with increasing rotation angle. The case which matches best with the experimental final arm length is the $15^{\circ}$ rotation. Yet the best matching shape of the grain projection is obtained with the $30^{\circ}$ rotation. For a rotation angle of $30^{\circ}, \mathrm{P} 26$ is $11 \%$ shorter and P45 is $12 \%$ shorter than in the experiments. In this way, for $30^{\circ}$ it is possible to obtain a RG that has a similar projection shape as that of the experimental observations, but a smaller surface area (homothetic).

When a primary arm of RG touches the upper or lower domain wall, due to the rotation around the axis $\hat{e}_{\text {rot }}$ (e.g. see Fig. $8 \mathrm{~b}$ where the RG is rotated $30^{\circ}$ around $\hat{e}_{\text {rot }}$ ), the growth is constrained along the wall normal direction $z$, i.e. the primary arm does not grow out of the domain. The growth is not constrained in the corresponding direction perpendicular to the wall normal direction (parallel to touched wall). Then, the primary arm tip velocity has no component along the normal wall direction but it has a component parallel to the touched wall.

Next, the influence of the position of the grain in the sample thickness ( $z$ direction) is investigated. In this way, three more three-dimensional simulation cases are run: C050, C075 and C100. These cases are identical to RC, but only the centroid 


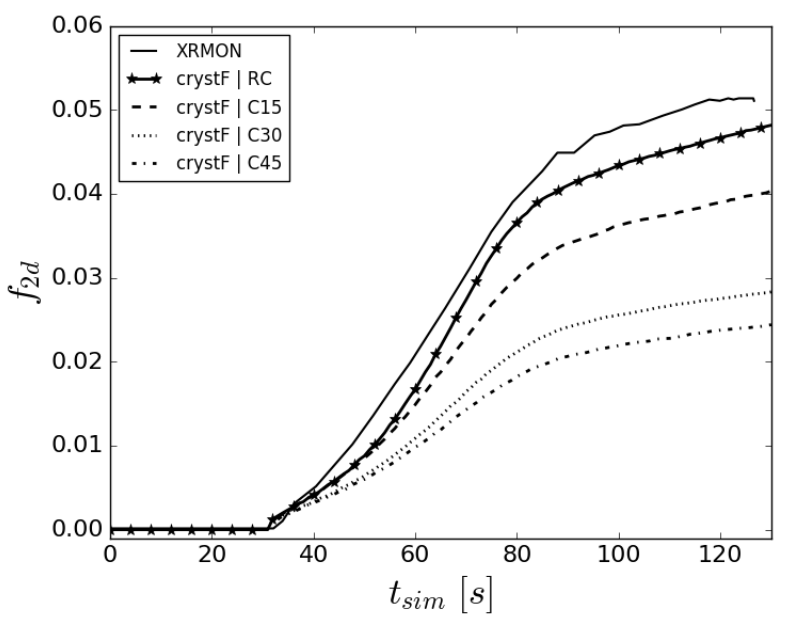

Figure 9: Evolution of the dimensionless envelope projected area, $f_{2 \mathrm{~d}}$, over time for the reference grain, $\mathrm{RG}$, where $f_{2 \mathrm{~d}}$ is the ratio of the projected grain area to the projected domain area $\left(f_{2 \mathrm{~d}}=A_{2 \mathrm{~d}} /\left(L_{\mathrm{x}} L_{\mathrm{y}}\right)\right)$. Four different three-dimensional simulation cases are shown: the case of reference (crystF $\mid \mathrm{RC}$ ), the case with $\mathrm{RG}$ rotated $15^{\circ}$ (crystF $\mid \mathrm{C} 15$ ), the case with $\mathrm{RG}$ rotated $30^{\circ}$ (crystF $\mid \mathrm{C} 30$ ), and the case with $\mathrm{RG}$ rotated $45^{\circ}$ (crystF $\mid \mathrm{C} 45$ ). Additionally, the experimental results of Murphy et al. [22] are also shown (XRMON).

of the nucleation seed of the reference grain (RG) is shifted. Its vertical coordinate is $z=-50 \mu \mathrm{m}, z=-75 \mu \mathrm{m}$ and $z=$ $-100 \mu \mathrm{m}$ for the cases C050, C075, and C100, respectively. The seeds of all other grains remain in the center $x-y$ plane, i.e., at $z=0$.

In Figs. 11a-c the numerical Beer-Lambert transmission at the final instant are shown for the cases C050, C075, and C100, respectively. The projected envelope shape of RG is not influenced by the vertical shift of the seed center. However the size of RG increases considerably for $\mathrm{C} 100$. In this case the seed of the RG is stuck to the wall $(z=-100 \mu \mathrm{m})$ and the four primary branches perpendicular to $z$ grow along this wall as half-branches (with the wall as their symmetry plane). Effectively these branches "feel" a lateral confinement two times larger than the sample thickness. As a consequence of the larger confinement the concentration gradient driving the solute diffusion at the tip increases and accelerates the tips. This can be seen in Figs. 8a and c. We could also expect that the shift in the vertical position of RG with respect to the other grains would change the solutal interaction and affect the growth of RG as well as of the neighboring grains. Yet this effect does not seem to be very important; Figs. 11a-c show that the shape and size of the neighbors of the RG are not altered.

For smaller vertical shifts, in cases C050 and C075, RG is only slightly affected. The transmission contrast decreases with the vertical shift of RG (mainly in cases C075 and C100) since the dendrite shape changes considerably when observed in 3D (see Fig. 8c for C100). While the amount of solid that constitutes the grain does not change as a consequence of the shift, the projected size of the envelope increases considerably due to the faster growth of the dendrite tips. This means that the volume fraction of the solid inside the envelope decreases, thus reducing the transmission contrast. A large shift with respect to
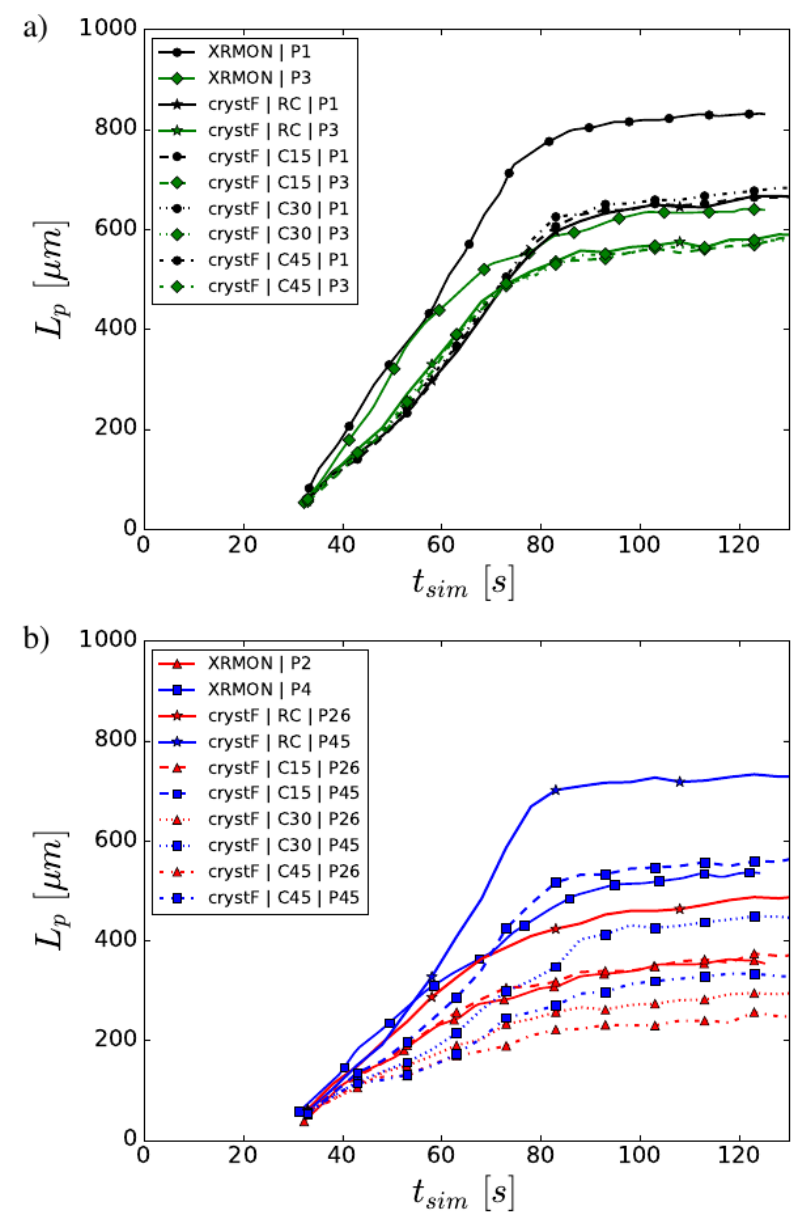

Figure 10: Evolution of equiaxed primary arm, $L_{\mathrm{p}}$, over time for the reference grain, RG. Four different three-dimensional simulation cases are shown: the case of reference (crystF $\mid \mathrm{RC}$ ), the case with $\mathrm{RG}$ rotated $15^{\circ}$ (crystF $\mid \mathrm{C} 15$ ), the case with $\mathrm{RG}$ rotated $30^{\circ}$ (crystF $\mid \mathrm{C} 30$ ), and the case with $\mathrm{RG}$ rotated $45^{\circ}$ (crystF $\mid \mathrm{C} 45$ ). Additionally, the experimental results of Murphy et al. [22] are also shown (XRMON). 
a)

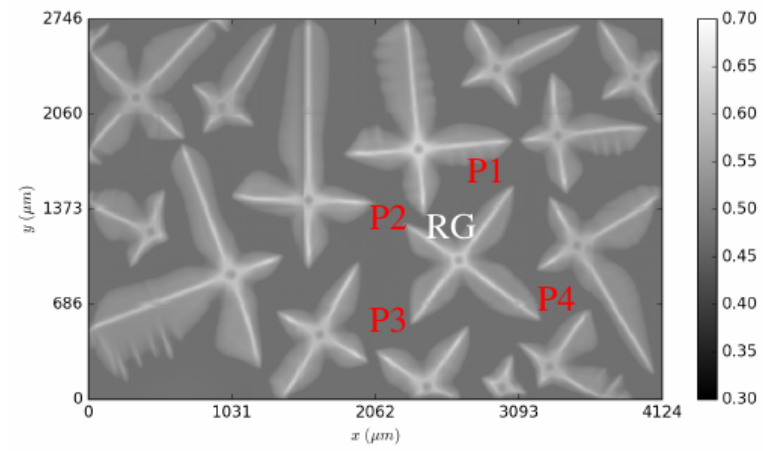

b)

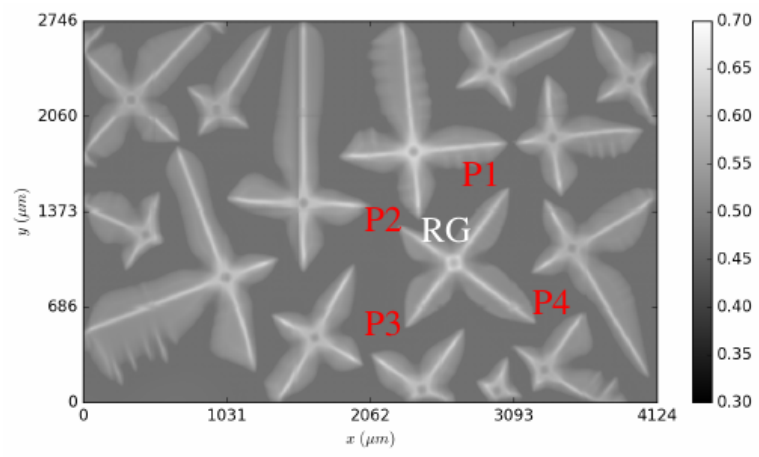

c)

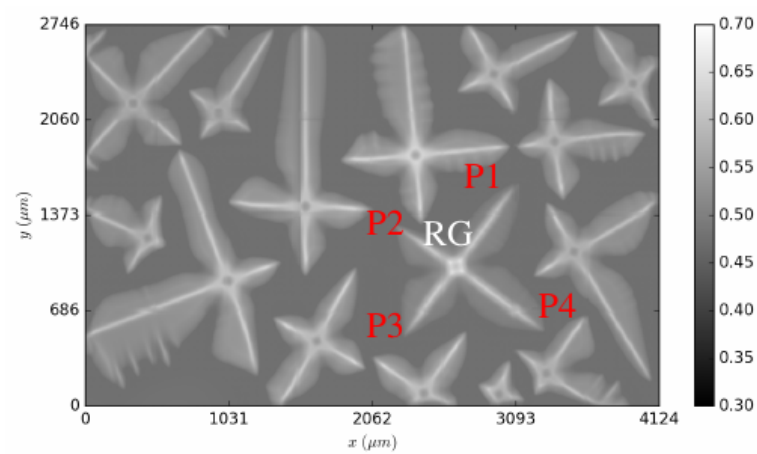

Figure 11: Numerical Beer-Lambert transmission at the final instant $t_{\mathrm{sim}}=130 \mathrm{~s}$ for a) the case with initial vertical position of the RG of $-50 \mu \mathrm{m}(\mathrm{C} 050)$, b) the case with initial vertical position of the RG of $-75 \mu \mathrm{m}(\mathrm{C} 075)$, and c) the case with initial vertical position of the RG of $-100 \mu \mathrm{m}(\mathrm{C} 100)$. The reference grain is indicated in the images, RG. The gray scale bar refers to the transmission coefficient, $T_{\mathrm{I}}$.

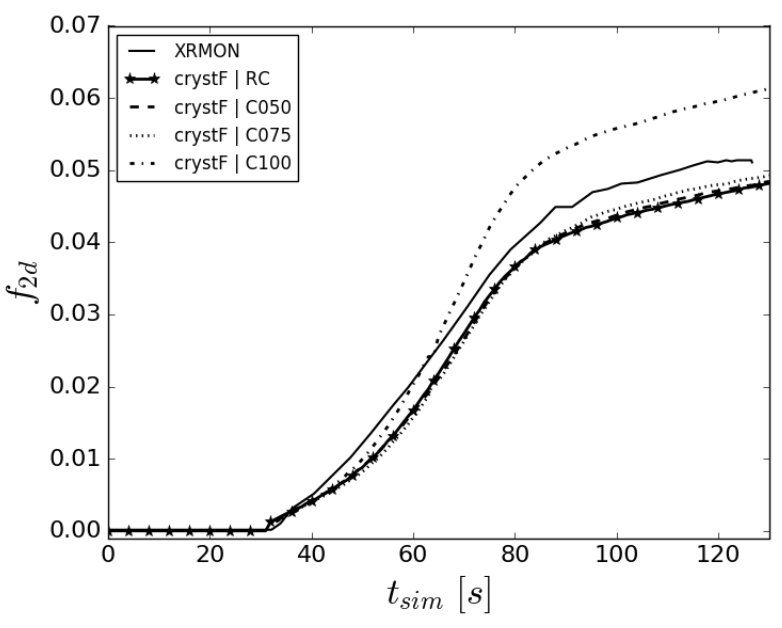

Figure 12: Evolution of the dimensionless envelope projected area, $f_{2 \mathrm{~d}}$, over time for the reference grain, $\mathrm{RG}$, where $f_{2 \mathrm{~d}}$ is the ratio of the projected grain area to the projected domain area $\left(f_{2 \mathrm{~d}}=A_{2 \mathrm{~d}} /\left(L_{\mathrm{x}} L_{\mathrm{y}}\right)\right)$. Four different threedimensional simulation cases are shown: the case of reference (crystF $\mid \mathrm{RC}$ ), the case with the initial vertical position of the RG of $-50 \mu \mathrm{m}$ (crystF $\mid \mathrm{C} 050$ ), the case with the initial vertical position of the RG of $-75 \mu \mathrm{m}$ (crystF $\mid \mathrm{C} 075$ ), and the case with the initial vertical position of the RG of $-100 \mu \mathrm{m}$ (crystF $\mid \mathrm{C} 100$ ). Additionally, the experimental results of Murphy et al. [22] are also shown (XRMON).

the plane $x-y$ also allows the development of a primary arm in the vertical direction, which was not possible in RC due to the top and bottom wall constrains.

Additionally, these results are discussed quantitatively. In Fig. 12 we show the time-evolution of $f_{2 \mathrm{~d}}$. The final projected area of $\mathrm{RG}$ in $\mathrm{C} 100$ increases by $36 \%$ with respect to the $\mathrm{RC}$, obtaining a much larger area than in the experimental observations. In Figs. 13a and $b$ the time-evolution of the primary arm length is shown. For C100 a similar increase of the final length with respect to RC, by approximately $70 \mu \mathrm{m}$, is observed for all four projected arms (P1-P4).

Finally, the influence of the combination of both the grain rotation and the grain position in the sample thickness ( $\mathrm{z}$ direction) is investigated. Three cases with a rotation of $45^{\circ}$ and with different positions in $z$ are considered: $\mathrm{C} 45+050, \mathrm{C} 45+075$, $\mathrm{C} 45+100$. These cases are identical to $\mathrm{C} 45$, but the centroid of the initial seed of the reference grain $(R G)$ is shifted. Its vertical coordinate is $z=-50 \mu \mathrm{m}, z=-75 \mu \mathrm{m}$ and $z=-100 \mu \mathrm{m}$ for the cases $\mathrm{C} 45+050, \mathrm{C} 45+075$, and $\mathrm{C} 45+100$, respectively. As in the previous simulations, the seeds of all other grains remain in the center $x-y$ plane, i.e., at $z=0$.

In Figs. 14a-c, we show the numerical Beer-Lambert transmissions at the final instant for the simulation cases $\mathrm{C} 45+050$, $\mathrm{C} 45+075$, and $\mathrm{C} 45+100$. The shape of the projection of the rotated grain $(\mathrm{RG})$ is slightly affected by the vertical shift of the seed center (see Figs. 14a-c) when compared to the case C45, where $\mathrm{RG}$ is rotated $45^{\circ}$ and the seed center is located at $z=0$. A slight change is appreciated in the apex shape of the projected arms: the larger the vertical shift is, the wider are their apex angles (at least for the tips contained in the rotation axis, ie. P1 and P3). The line joining P26 and P45 is bright as in case C45, and the darker line joining $\mathrm{P} 1$ and $\mathrm{P} 3$ is more distinguishable 

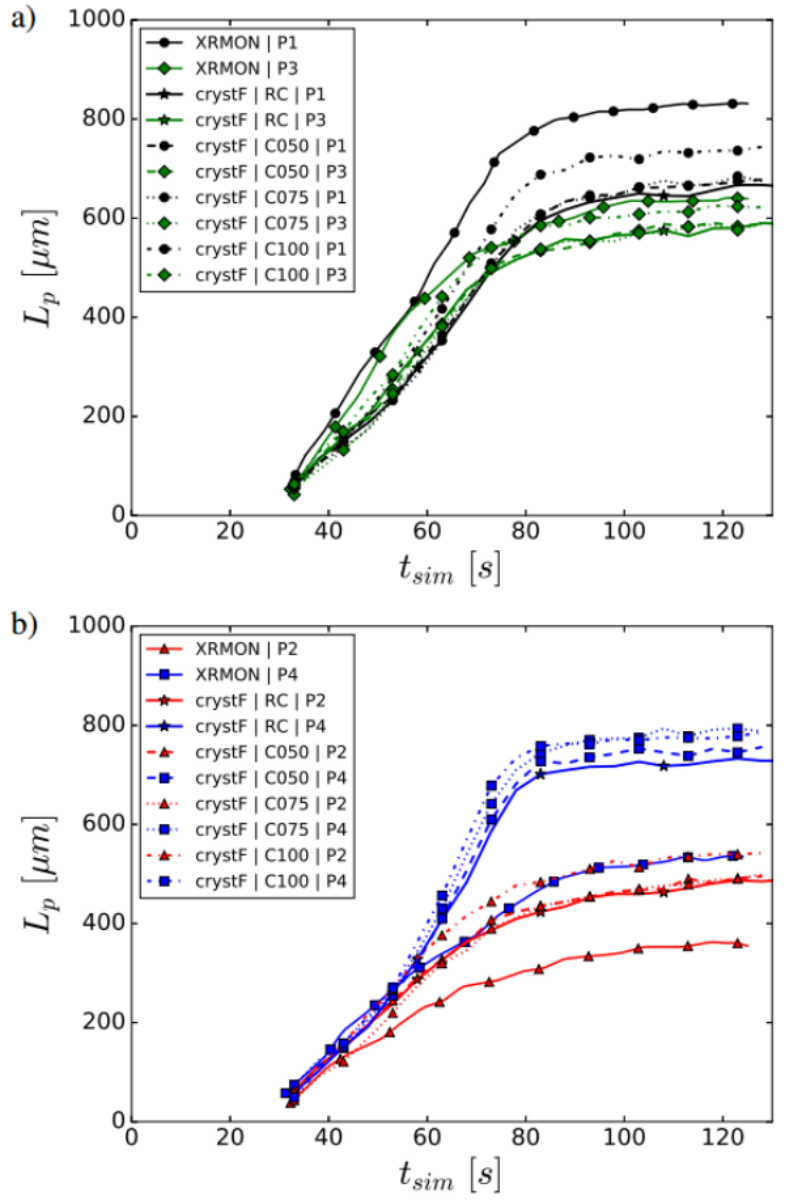

Figure 13: Evolution of equiaxed primary arm, $L_{\mathrm{p}}$, over time for the reference grain, RG. Four different three-dimensional simulation cases are shown: the case of reference (crystF $\mid \mathrm{RC}$ ), the case with the initial vertical position of the RG of $-50 \mu \mathrm{m}$ (crystF $\mid \mathrm{C} 050)$, the case with the initial vertical position of the RG of $-75 \mu \mathrm{m}$ (crystF $\mid \mathrm{C} 075$ ), and the case with the initial vertical position of the RG of $-100 \mu \mathrm{m}$ (crystF | C100). Additionally, the experimental results of Murphy et al. [22] are also shown (XRMON). a)

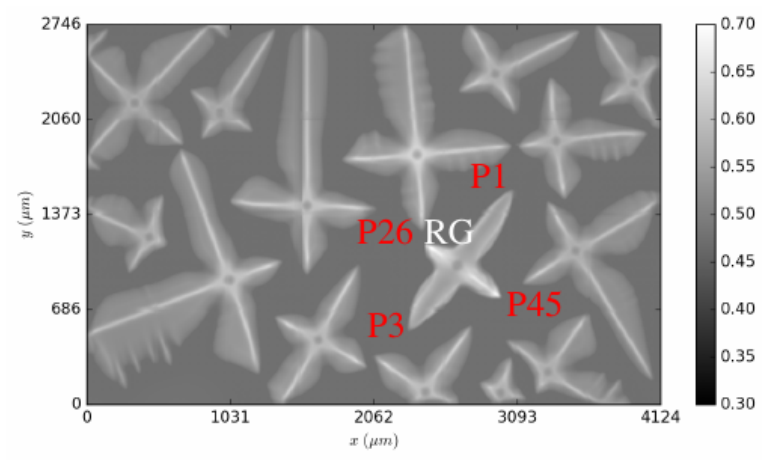

b)

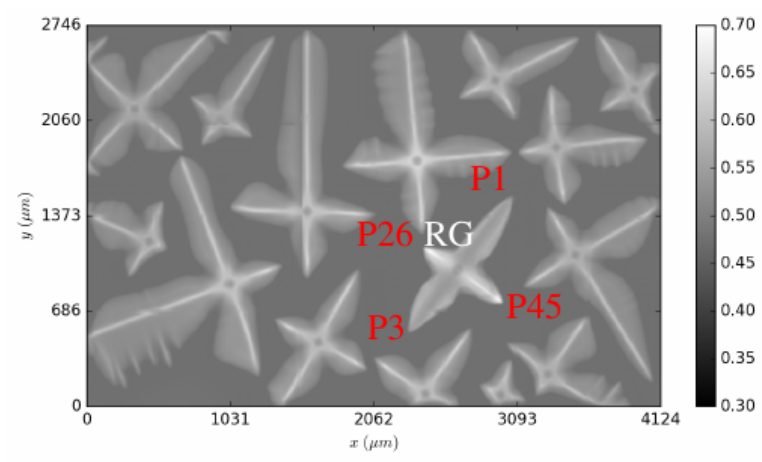

c)

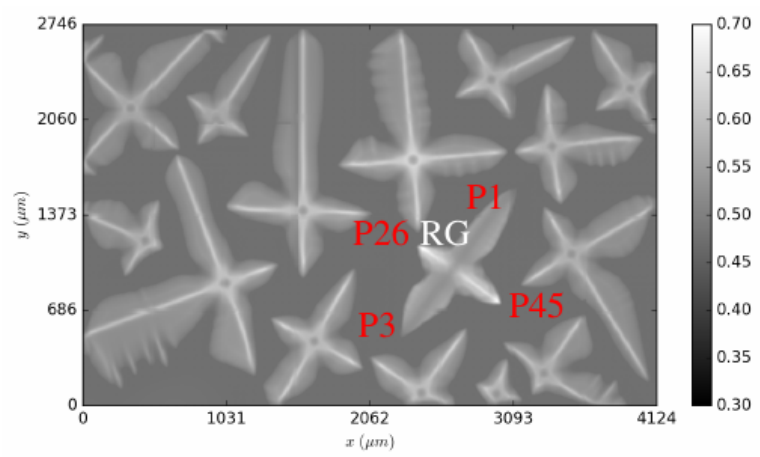

Figure 14: Numerical Beer-Lambert transmission at the final instant $t_{\mathrm{sim}}=$ $130 \mathrm{~s}$ for a) the case with $\mathrm{RG}$ rotated $45^{\circ}$ and initial vertical position of $-50 \mu \mathrm{m}$ $(\mathrm{C} 45+050)$, b) the case with $\mathrm{RG}$ rotated $45^{\circ}$ and initial vertical position of $-75 \mu \mathrm{m}(\mathrm{C} 45+075)$, and $\mathrm{c})$ the case with $\mathrm{RG}$ rotated $45^{\circ}$ and initial vertical position of $-100 \mu \mathrm{m}(\mathrm{C} 45+100)$. The reference grain is indicated in the images, RG. The gray scale bar refers to the transmission coefficient, $T_{\mathrm{I}}$.

with the vertical shift.

Although the projection shape is not significantly affected, the three-dimensional shape of the rotated RG is strongly modified by the vertical shift (see Figs. 8 b and c). The grain develops normally along the directions $(1,0,0)$ and $(-1,0,0)$ in body axis (P1 and $\mathrm{P} 3$, respectively). The directions $(0,1,0)$ and $(0,0,1)$ in body axis (P2 and $\mathrm{P} 5$, respectively) develop until they get stuck to the upper wall $z=100$. The tips P4 and P6 do not clearly develop in this case.

The impact of the vertical shift on the projected area over time $\left(f_{2 \mathrm{~d}}\right)$ of the rotated RG is shown in Fig. 15. The projected area increases with the vertical shift; however, for all shifts smaller projected areas than the experimental observations are obtained. In Fig. 16 we show the time-evolution of the projected primary arm length. The arm length of the four 


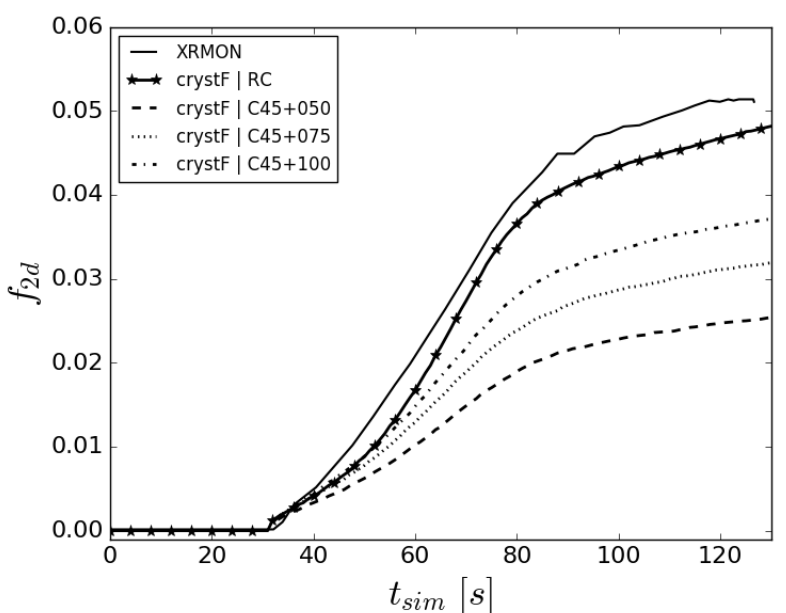

Figure 15: Evolution of the dimensionless envelope projected area, $f_{2 \mathrm{~d}}$, over time for the reference grain, RG, where $f_{2 \mathrm{~d}}$ is the ratio of the projected grain area to the projected domain area $\left(f_{2 \mathrm{~d}}=A_{2 \mathrm{~d}} /\left(L_{\mathrm{x}} L_{\mathrm{y}}\right)\right)$. Four different three-dimensional simulation cases are shown: the case of reference (crystF $\mid \mathrm{RC}$ ), the case with $\mathrm{RG}$ rotated $45^{\circ}$ and its initial vertical position of $-50 \mu \mathrm{m}$ (crystF $\mid \mathrm{C} 45+050$ ), the case with $\mathrm{RG}$ rotated $45^{\circ}$ and its initial vertical position of $-75 \mu \mathrm{m}$ (crystF $\mid \mathrm{C} 45+075)$, and the case with $\mathrm{RG}$ rotated $45^{\circ}$ and its initial vertical position of $-100 \mu \mathrm{m}$ (crystF $\mid \mathrm{C} 45+100$ ). Additionally, the experimental results of Murphy et al. [22] are also shown (XRMON).

projections slightly increases with the vertical shift, although all four are shorter than the experimental observations.

Among all the three-dimensional simulation cases carried out to investigate the effect of rotation and position along the sample thickness, the cases $\mathrm{C} 30$ and $\mathrm{C} 45+100$ have projection shapes of the reference grain (RG) which are very similar to that of the experimental observations. However, the case C45+100 gives a better match for the length of the primary arms and also provides a transmission map for the RG which corresponds to that of the experimental observations (with similar bright and dark lines joining the tips P24-P45 and P1-P3, respectively). We can conclude that the RG in Murphy et al. [22] may have similar rotation and shift than the case $\mathrm{C} 45+100$.

\section{Conclusions}

We investigated the grain growth kinetics of the equiaxed dendritic isothermal solidification of a thin sample of a binary alloy (Al-20 wt.\% Cu) by means of a 3D mesoscopic envelope model and compared the numerical results with the experimental X-ray transmission observations in [22]. The system is composed of 15 equiaxed dendritic grains that grow along the three dimensions $x, y$, and $z$. The only model parameter - the stagnant film thickness, $\delta$ - is carefully calibrated and the predicted grain morphology in the studied case is shown to have only small sensitivity to $\delta$. The mesoscopic model is capable of describing solutal grain interactions down to short distances between grains. The $3 \mathrm{D}$ grain structure is shown to play an important role for the description of the growth kinetics. The impact of three three-dimensional aspects was investigated:

- The impact of incorporating the thin direction on the solutal diffusion. The solute diffusion was solved in 3D and in
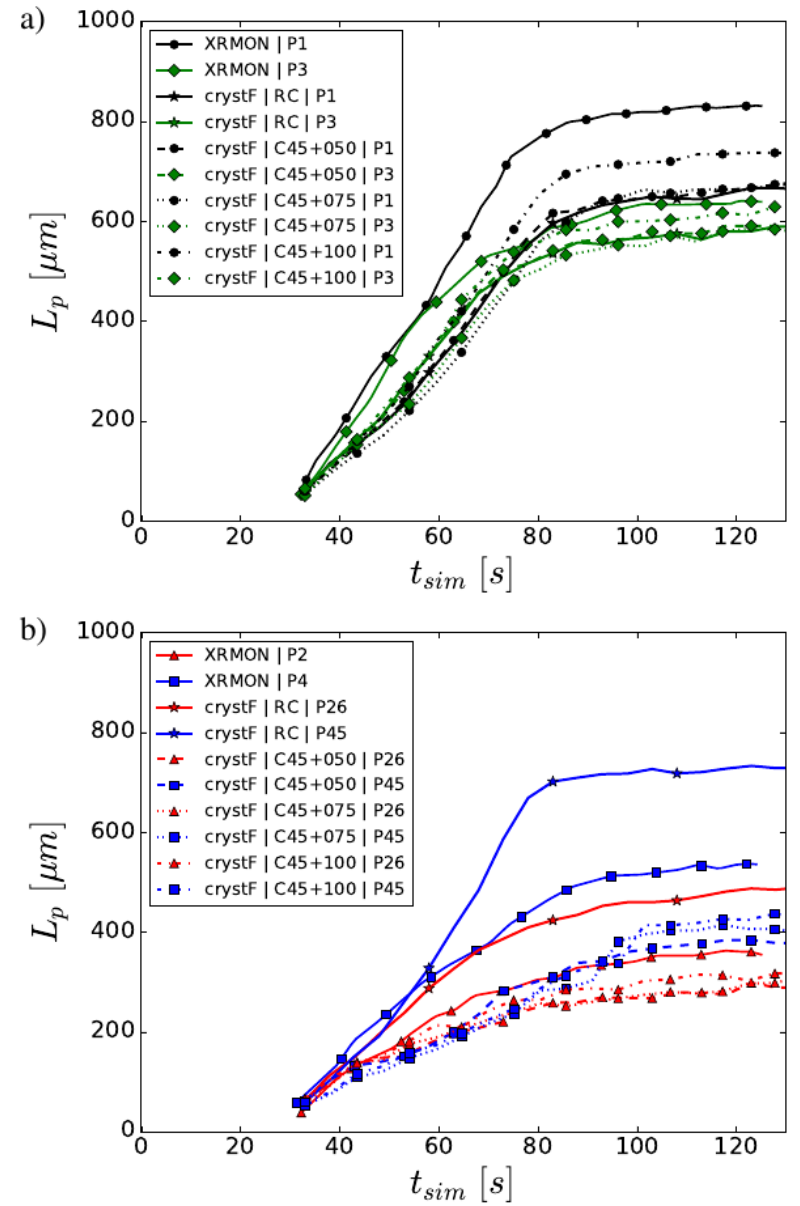

Figure 16: Evolution of equiaxed primary arm, $L_{\mathrm{p}}$, over time for the reference grain, RG. Four different three-dimensional simulation cases are shown: the case of reference (crystF $\mid \mathrm{RC}$ ), the case with $\mathrm{RG}$ rotated $45^{\circ}$ and its initial vertical position of $-50 \mu \mathrm{m}$ (crystF $\mid \mathrm{C} 45+050)$, the case with $\mathrm{RG}$ rotated $45^{\circ}$ and its initial vertical position of $-75 \mu \mathrm{m}$ (crystF $\mid \mathrm{C} 45+075)$, and the case with $\mathrm{RG}$ rotated $45^{\circ}$ and its initial vertical position of $-100 \mu \mathrm{m}$ (crystF $\left.\mid \mathrm{C} 45+100\right)$. Additionally, the experimental results of Murphy et al. [22] are also shown (XRMON). 
2D (neglecting the thin sample dimension). The dendritic grain size was shown to increase by almost twice when the thin dimension is considered.

- The impact of the misalignment of the grain preferential growth directions $\langle 100\rangle$ with respect to $z$. A reference grain was rotated around an axis contained in the center plane $x-y$, showing an important influence on the growth kinetics that considerably affects the grain shape. In the transmission image, the primary arms perpendicular to the rotation axis shorten with rotation.

- The influence of the position of the grain center along the sample thickness, $z$. A reference grain is shifted with respect to the central plane $x-y$. We show that faster growth kinetics is obtained when the reference grain is shifted to the wall of the sample whereas negligible effect on the growth kinetics is found when the grain is slightly shifted with respect to the central plane. For none of the shift simulations, an effect on grain shape is found.

Further work should be focus on three points: a) the influence of the natural convection on the growth kinetics in thin samples [39]; b) the development of more complex simulations where the dendritic growth, natural convection and motion of the grains are coupled; and c) a better understanding of estimation of the stagnant film thickness.

\section{Acknowledgements}

This work was supported by the French State through the program "Investment in the future" operated by the National Research Agency (ANR) and referenced by ANR-11 LABX0008-01 (LabEx DAMAS). High Performance Computing resources were partially provided by the EXPLOR centre hosted by the University de Lorraine. We thank David J. Browne, Henri Nguyen Thi, Guillaume Reinhart, and Michel Rappaz for helpful comments and discussions.

\section{Appendix A. Model calibration}

The stagnant film thickness, $\delta$, is a fundamental model parameter. It determines the coupling between the solute concentration field around the grain envelope and the envelope growth rate. The local growth velocity of the envelope is determined by the velocity of the dendrite tips. The growth Péclet number of the tips, $P e_{\text {tip }}$, is calculated from the supersaturation of the liquid at a finite distance, $\delta$, from the tip, $\Omega_{\delta}$, using a stagnant film formulation of the Ivantsov solution for a paraboloidal dendrite tip [24]: $\Omega_{\delta}=$ $P e_{\text {tip }} \exp \left(P e_{\text {tip }}\right)\left[E_{1}\left(P e_{\text {tip }}\right)-E_{1}\left(P e_{\text {tip }}\left[1+2 \delta / R_{\text {tip }}\right]\right)\right]$. The supersaturation $\Omega_{\delta}=\left(C_{1}^{*}-C_{1, \delta}\right) /\left(C_{1}^{*}(1-k)\right)$ is defined by the liquid concentration at the envelope, $C_{1}^{*}$, and the concentration in the liquid at distance $\delta$ orthogonally to the envelope, $C_{1, \delta}$. The latter is obtained from the fully resolved concentration field in the liquid around the envelope [15]. Finally, a tip selection criterion is used to calculate the tip growth velocity from the Péclet a)
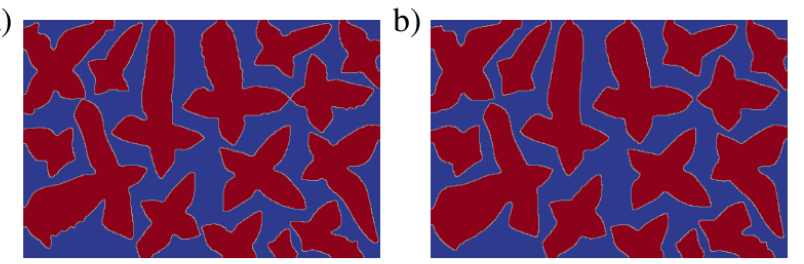

c)
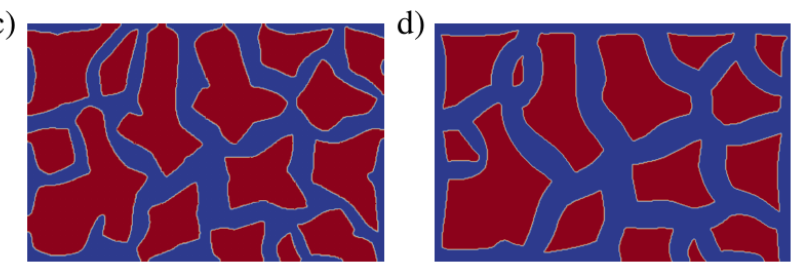

Figure A.17: Central slice, plane $x-y$, of three-dimensional simulations showing the dendritic envelope morphology at $t_{\mathrm{sim}}=130 \mathrm{~s}$ for 4 different values of the stagnant film thickness, $\delta_{\mathrm{c}}$, of: a) $20 \mu \mathrm{m}$ (RC), b) $40 \mu \mathrm{m}$, c) $100 \mu \mathrm{m}$, and d) $200 \mu \mathrm{m}$.

number: $V_{\text {tip }}=4 \sigma^{*} D_{1} P e_{\text {tip }}^{2} / d_{0}$, where $d_{0}=\Gamma /\left(m_{\mathrm{L}} C_{1}^{*}(k-1)\right.$ is the capillary length.

For simplicity, the model considers $\delta$ to be constant in time and identical for all points on all envelopes. In previous work $[15,16]$ it was shown that a good choice was to set $\delta$ equal to the characteristic diffusion length, $D_{1} / \bar{V}_{t i p}$, where $\bar{V}_{t i p}$ is a representative tip velocity. Considering the maximum of the concentration difference $\overline{\Delta C_{1}}$ between the envelope and the far field in the liquid in the sample to be between 0.5 and $1.0 \mathrm{wt} . \%$, growth velocities ranging from 3 to $16 \mu \mathrm{m} / \mathrm{s}$ are found (similar to the growth velocities in the experimental observation [22]). The result of a simulation using this scaling, $\delta=D_{1} / \bar{V}_{\text {tip }} \sim 200 \mu \mathrm{m}$, is shown in Fig. A.17d. However with this approach, the final envelope shapes are clearly not realistic.

Simulations using smaller values of $\delta$ show that the apexangle of the primary arms decreases with smaller $\delta$ (see Fig. A.17a-c). An equivalent trend is reported in [32]. Realistic envelope shapes are obtained for $\delta \leq 40 \mu \mathrm{m}$. We can note that this is closer to the diffusion length at the dendrite tip scale, which is obtained from the Ivantsov solution [23] and scales as $\bar{\Omega} D_{1} / \bar{V}_{t i p}$ where $\bar{\Omega}=\Delta C_{1} /\left(C_{1}^{*}\left(1-k_{\mathrm{p}}\right)\right)$. We estimate the diffusion length at the dendrite tip scale to range between 10 and $30 \mu \mathrm{m}$ for $\overline{\Delta C_{1}}$ between 0.5 and $1.0 \mathrm{wt} . \%$.

The rigorous mathematical estimation of the stagnant film thickness $\delta$ is still an open question. In this publication we have chosen the stagnant film thickness to be equal to the diffusion length at the tip scale $\delta=\bar{\Omega} D_{1} / \bar{V}_{t i p} \approx 20 \mu \mathrm{m}$. Additionally, as we can see in Figs. A.17a and b the grain morphology sensitivity on $\delta$ is low when $\delta$ is within this order of magnitude. In case of using a stagnant film thickness of $40 \mu \mathrm{m}$ instead of $20 \mu \mathrm{m}$, we obtain for the reference grain (RG) $5.4 \%$ relatively shorter projected primary arms and a projected area $3.5 \%$ larger. In this way, we establish the relative error associated to the adjustable parameter $\delta$ equal to $5.4 \%$ and $3.5 \%$ for the length of the projected arms and projected area, respectively. 


\section{Appendix B. Numerical Beer-Lambert transmission}

The classical Beer-Lambert law, which relates the absorption of light crossing a material to its properties, is given by [40]:

$$
T_{\mathrm{I}}=e^{-\int_{-L_{\mathrm{Z}} / 2}^{+L_{\mathrm{Z}} / 2} \mu(\xi) d \xi}
$$

where $T_{\mathrm{I}}$ is the transmission coefficient, $\mu$ is the absorption coefficient, and $L_{\mathrm{z}}$ is the sample thickness. The transmission coefficient is given by the ratio of the transmitted intensity after passing through the material, $I_{\mathrm{T}}$, to the intensity of the incident beam, $I_{0}$. The absorption coefficient can be written as a function of the material density, $\rho$, and the mass absorption coefficient, $\mu^{\prime}: \mu=\rho \mu^{\prime}$. The mass absorption coefficient of a metal alloy can be written as a function of the alloy composition [41]: $\mu^{\prime}=\sum_{\mathrm{i}} \mu_{\mathrm{i}}^{\prime} C_{\mathrm{i}}$, where $\mu_{\mathrm{i}}^{\prime}$ and $C_{\mathrm{i}}$ are the mass absorption coefficient and mass fraction of the alloy element $i$. According to [42], the mass absorption coefficient (of each element i) is only weakly dependent on the physical state of the material (solid or liquid) and on the temperature. As an approximation we can assume them constant. For the Al-20 wt $\% \mathrm{Cu}$ alloy we write the mass absorption coefficient as a function of the copper mass fraction, $C_{\mathrm{Cu}}$, and alloy density, $\rho$ :

$$
\mu \approx \rho\left(\mu_{\mathrm{Al}}^{\prime}+\left(\mu_{\mathrm{Cu}}^{\prime}-\mu_{\mathrm{Al}}^{\prime}\right) C_{\mathrm{Cu}}\right)
$$

The absorption coefficients of the elements can vary by orders of magnitude as a function of the photon energy, which makes the calculation of the transmittance for a polychromatic beam, such as the one used in the XRMON-SOL experiments [22], very complex [43]. Calibrations for quantitative concentration measurements using such beams have been proposed [43], but are not known for the setup simulated here. In absence of more detailed data we used the absorption coefficients given by Salloum-Abou-Jaoude for a monochromatic beam [40]. Because the numerical Beer-Lambert transmissions in Section 4 are only used to identify the projected envelope contours and for visual comparisons, their quantitative accuracy is not a prime concern here. Mass absorption coefficients of approximately $0.3441 \mathrm{~m}^{2} / \mathrm{kg}$ and $3.379 \mathrm{~m}^{2} / \mathrm{kg}$ were used for pure aluminum and copper, respectively [40].

Additionally we write the material density as a function of the temperature and copper mass fraction:

$$
\rho\left(T, C_{\mathrm{Cu}}\right)=\left(1-C_{\mathrm{Cu}}\right) \rho_{\mathrm{Al}}(T)+C_{\mathrm{Cu}}, \rho_{\mathrm{Cu}}(T),
$$

where the density dependence on temperature for aluminum and copper is linearized:

$$
\begin{aligned}
& \rho_{\mathrm{Al}}(T)=\rho_{\mathrm{Al}_{\mathrm{ref}}}+\frac{\rho_{\mathrm{Al}_{\mathrm{m}}}-\rho_{\mathrm{Al}_{\mathrm{ref}}}}{T_{\mathrm{m}}-T_{\mathrm{ref}}}\left(T-T_{\mathrm{ref}}\right) \\
& \rho_{\mathrm{Cu}}(T)=\rho_{\mathrm{Cu}_{\mathrm{ref}}}+\frac{\rho_{\mathrm{Cu}_{\mathrm{m}}}-\rho_{\mathrm{Cu}_{\mathrm{ref}}}}{T_{\mathrm{m}}-T_{\mathrm{ref}}}\left(T-T_{\mathrm{ref}}\right) .
\end{aligned}
$$

A reference temperature, $T_{\text {ref }}$, of $25^{\circ}$ and a melting temperature, $T_{\mathrm{m}}$, of $660^{\circ}$ were used. The corresponding densities for aluminum and copper at reference and melting temperatures are collected in Table B.2.
Table B.2: Densities of aluminum and copper at reference and melting temperatures [40].

\begin{tabular}{ccc}
\hline \hline $\mathrm{i}$ & $\rho_{\mathrm{i} \text { ref }}\left[\mathrm{kg} / \mathrm{m}^{3}\right]$ & $\rho_{\mathrm{im}}\left[\mathrm{kg} / \mathrm{m}^{3}\right]$ \\
\hline $\mathrm{Al}$ & 2700 & 2375 \\
\hline $\mathrm{Cu}$ & 8960 & 8278 \\
\hline \hline
\end{tabular}

\section{References}

[1] J. A. Dantzig, M. Rappaz, Solidification, EPFL Press, 1st edition, 2009.

[2] J. Bragard, A. Karma, Y. H. Lee, M. Plapp, Linking Phase-Field and Atomistic Simulations to Model Dendritic Solidification in Highly Undercooled Melts, Interface Science 10 (2002) 121-136.

[3] A. K. Boukellal, J.-M. Debierre, G. Reinhart, H. Nguyen-Thi, Scaling laws governing the growth and interaction of equiaxed $\mathrm{Al}-\mathrm{Cu}$ dendrites: A study combining experiments with phase-field simulations, Materialia 1 (2018) 62-69.

[4] T. Takaki, Phase-field modeling and simulations of dendrite growth, ISIJ International 54 (2014) 437-444.

[5] A. Jacot, M. Rappaz, A pseudo-front tracking technique for the modelling of solidification microstructures in multi-component alloys, Acta Materialia 50 (2002) 1909 - 1926.

[6] V. R. Voller, An enthalpy method for modeling dendritic growth in a binary alloy, International Journal of Heat and Mass Transfer 51 (2008) $823-834$.

[7] D. Li, R. Li, P. Zhang, A cellular automaton technique for modelling of a binary dendritic growth with convection, Applied Mathematical Modelling 31 (2007) $971-982$.

[8] L. Sturz, A. Theofilatos, Two-dimensional multi-scale dendrite needle network modeling and $\mathrm{x}$-ray radiography of equiaxed alloy solidification in grain-refined Al-3.5 wt-\%Ni, Acta Materialia 117 (2016) 356-370.

[9] D. Tourret, A. Karma, A. J. Clarke, P. J. Gibbs, S. D. Imhoff, Threedimensional Dendritic Needle Network model with application to Al-Cu directional solidification experiments, IOP Conference Series: Materials Science and Engineering 84 (2015).

[10] D. R. Liu, G. Reinhart, N. Mangelinck-Noel, C.-A. Gandin, H. NguyenThi, B. Billia, Coupled Cellular Automaton (CA) - Finite Element (FE) Modeling of Directional Solidification of Al-3.5 wt Ni Alloy: A Comparison with X-ray Synchrotron Observations, ISIJ International 54 (2014) 392-400.

[11] T. Carozzani, H. Digonnet, C.-A. Gandin, 3D CAFE modeling of grain structures: application to primary dendritic and secondary eutectic solidification, Modelling and Simulation in Materials Science and Engineering 20 (2012).

[12] I. Steinbach, C. Beckermann, B. Kauerauf, Q. Li, J. Guo, Threedimensional modeling of equiaxed dendritic growth on a mesoscopic scale, Acta Materialia 47 (1999) 971 - 982.

[13] I. Steinbach, H.-J. Diepers, C. Beckermann, Transient growth and interaction of equiaxed dendrites, Journal of Crystal Growth 275 (2005) 624 -638 .

[14] P. Delaleau, C. Beckermann, R. H. Mathiesen, L. Arnberg, Mesoscopic simulation of dendritic growth observed in X-ray video microscopy during directional solidification of AlCu alloys, ISIJ International 50 (2010) 1886-1894.

[15] Y. Souhar, V. F. De Felice, C. Beckermann, H. Combeau, M. Založnik, Three-dimensional mesoscopic modeling of equiaxed dendritic solidification of a binary alloy, Computational Materials Science 112 (2016) $304-317$.

[16] A. Viardin, M. Založnik, Y. Souhar, M. Apel, H. Combeau, Mesoscopic modeling of spacing and grain selection in columnar dendritic solidification: Envelope versus phase-field model, Acta Materialia 122 (2017) 386 -399 .

[17] M. Založnik, A. Viardin, Y. Souhar, H. Combeau, M. Apel, Mesoscopic modeling of columnar solidification and comparisons with phase-field simulations, IOP Conference Series: Materials Science and Engineering 84 (2015).

[18] M. Založnik, H. Combeau, An operator splitting scheme for coupling macroscopic transport and grain growth in a two-phase multiscale solid- 
ification model: Part I - Model and solution scheme, Computational Materials Science 48 (2010) $1-10$.

[19] M. Založnik, Y. Souhar, C. Beckermann, H. Combeau, Upscaling from Mesoscopic to Macroscopic Solidification Models by Volume Averaging, in: Frontiers of Solidification Science, TMS Annual Meeting 2016, TMS, Nashville, USA, 2016, pp. 59-63.

[20] M. Torabi Rad, M. Založnik, H. Combeau, C. Beckermann, Constitutive relations for macroscopic modelling of equiaxed solidification, in: Z. Fan (Ed.), Solidification Processing 2017: Proceedings of the 6th Decennial International Conference on Solidification Processing, Brunel University, London, UK, 2017, pp. 326-329.

[21] S. Akamatsu, H. Nguyen-Thi, In situ observation of solidification patterns in diffusive conditions, Acta Materialia 108 (2016) 325-346.

[22] A. G. Murphy, R. H. Mathiesen, Y. Houltz, J. Li, C. Lockowandt, K. Henriksson, G. Zimmermann, N. Melville, D. J. Browne, XRMON-SOL: Isothermal equiaxed solidification of a grain refined Al- $20 \mathrm{wt}-\% \mathrm{Cu}$, Journal of Crystal Growth 440 (2016) 38 - 46.

[23] G. P. Ivantsov, Dokl Akad Nauk SSSR 58 (1947) 567 - 570.

[24] B. Cantor, A. Vogel, Dendritic solidification and fluid flow, Journal of Crystal Growth 41 (1977) 109 - 123.

[25] Y. Sun, C. Beckermann, Sharp interface tracking using the phase-field equation, Journal of Computational Physics 220 (2007) 626 - 653.

[26] Y. Sun, C. Beckermann, A two-phase diffuse-interface model for hele-shaw flows with large property contrasts, Physica D: Nonlinear Phenomena 237 (2008) 3089 - 3098.

[27] H. G. Weller, G. Tabor, H. Jasak, C. Fureby, A tensorial approach to computational continuum mechanics using object-oriented techniques, Computers in Physics 12 (1998) 620.

[28] M. Becker, Solidification kinetics in Al-Cu and Al-Ge alloys investigated by in-situ X-ray radiography, Phd thesis, RWTH Aachen, 2017.

[29] J. S. Langer, H. Müller-Krumbhaar, Theory of dendritic growth - I. Elements of a stability analysis, Acta Metallurgica 26 (1978) 1681 - 1687.

[30] A. G. Murphy, R. H. Mathiesen, Y. Houltz, J. Li, C. Lockowandt, K. Henriksson, N. Melville, D. J. Browne, Direct observation of spatially isothermal equiaxed solidification of an Al-Cu alloy in microgravity on board the MASER 13 sounding rocket, Journal of Crystal Growth 454 (2016) $96-104$.

[31] A. Sémoroz, S. Henry, M. Rappaz, Application of the phase-field method to the solidification of hot-dipped galvanized coatings, Metallurgical and Materials Transactions A: Physical Metallurgy and Materials Science 31 (2000) 487-495.

[32] Y. Souhar, V. F. De Felice, M. Založnik, H. Combeau, C. Beckermann, The role of the stagnant-film thickness in mesoscopic modeling of equiaxed grain envelopes, IOP Conference Series: Materials Science and Engineering 117 (2016).

[33] D. A. Kessler, H. Levine, Velocity selection in dendritic growth, Phys. Rev. B 33 (1986) 7867-7870.

[34] B. P. Athreya, J. A. Dantzig, S. Liu, R. Trivedi, On the role of confinement on solidification in pure materials and binary alloys, Philosophical Magazine 86 (2006) 3739-3756.

[35] A. J. Clarke, D. Tourret, Y. Song, S. D. Imhoff, P. J. Gibbs, J. W. Gibbs, K. Fezzaa, A. Karma, Microstructure selection in thin-sample directional solidification of an Al-Cu alloy: In situ X-ray imaging and phase-field simulations, Acta Materialia 129 (2017) 203-216.

[36] D. Tourret, J. C. E. Mertens, E. Lieberman, S. D. Imhoff, J. W. Gibbs, K. Henderson, K. Fezzaa, A. L. Deriy, T. Sun, R. A. Lebensohn, B. M Patterson, A. J. Clarke, From solidification processing to microstructure to mechanical properties: a multi-scale X-ray study of an $\mathrm{Al}-\mathrm{Cu}$ alloy sample, Metallurgical and Materials Transactions A 48 (2017) 55295546.

[37] A. Murphy, In Situ X-Ray Monitoring of Advanced Alloy Solidification Processes under Microgravity and Terrestrial Conditions, Phd thesis, University College Dublin, 2013.

[38] D. J. Browne, Personal Communication, 2 May 2018.

[39] A. Olmedilla, M. Založnik, H. Combeau, Three-dimensional mesoscopic modeling of equiaxed dendritic solidification in a thin sample: effect of convection flow, IOP Conf. Series: Materials Science and Engineering (in press).

[40] G. Salloum-Abou-Jaoude, In situ investigation by X-ray radiography of microstructure evolution during solidification of binary alloys, $\mathrm{Ph} . \mathrm{D}$. thesis, Universite d'Aix-Marseille, 2014.
[41] H. Yin, J. N. Koster, Chemical stratification and solidification in a differentially heated melt, Journal of Alloys and Compounds 352 (2003) 197 209.

[42] K. Lonsdale, C. H. MacGillavry, International tables for X-ray crystallography, volume 3, D. Reidel, Dordrecht; Boston, 1985.

[43] M. Becker, S. Klein, F. Kargl, In-situ solute measurements with a laboratory polychromatic microfocus X-ray source during equiaxed solidification of an Al-Ge alloy, Scripta Materialia 124 (2016) 34-37. 